OPEN ACCESS

Edited by:

Wei Peng,

Chengdu University of Traditional

Chinese Medicine, China

Reviewed by:

Bin Li,

Army Medical University, China Lichuan Wu,

Guangxi University, China

*Correspondence:

Cheng Guo

guopharm@126.com

Specialty section:

This article was submitted to

Ethnopharmacology,

a section of the journal

Frontiers in Pharmacology

Received: 11 September 2019

Accepted: 16 April 2020

Published: 07 May 2020

Citation:

Zhang $H$, Chen L, Sun X, Yang $Q$,

Wan L and Guo C (2020) Matrine: A

Promising Natural Product With

Various Pharmacological Activities.

Front. Pharmacol. 11:588.

doi: 10.3389/fphar.2020.00588

\section{Matrine: A Promising Natural Product With Various Pharmacological Activities}

\author{
Hong Zhang ${ }^{1,2}$, Linlin Chen ${ }^{1,2}$, Xipeng Sun ${ }^{1}$, Quanjun Yang ${ }^{1}$, Lili Wan ${ }^{1}$ and Cheng Guo ${ }^{1,2 *}$ \\ ${ }^{1}$ Department of Pharmacy, Shanghai Sixth People's Hospital, Shanghai Jiao Tong University, Shanghai, China, ${ }^{2}$ School of \\ Medicine, Shanghai Jiao Tong University, Shanghai, China
}

Matrine is an alkaloid isolated from the traditional Chinese medicine Sophora flavescens Aiton. At present, a large number of studies have proved that matrine has an anticancer effect can inhibit cancer cell proliferation, arrest cell cycle, induce apoptosis, and inhibit cancer cell metastasis. It also has the effect of reversing anticancer drug resistance and reducing the toxicity of anticancer drugs. In addition, studies have reported that matrine has a therapeutic effect on Alzheimer's syndrome, encephalomyelitis, asthma, myocardial ischemia, rheumatoid arthritis, osteoporosis, and the like, and its mechanism is mainly related to the inhibition of inflammatory response and apoptosis. Its treatable disease spectrum spans multiple systems such as the nervous system, circulatory system, and immune system. The antidisease effect and mechanism of matrine are diverse, so it has high research value. This review summarizes recent studies on the pharmacological mechanism of matrine, with a view to providing reference for subsequent research.

Keywords: matrine, cancer, inflammation, apoptosis, autophagy, cell cycle, natural product

\section{INTRODUCTION}

Traditional Chinese medicine Kushen is the dry root of the leguminous plant Sophora flavescens Aiton, which has a long history of medicinal use in China. It is commonly used in the clinical treatment of traditional Chinese medicine for dysentery, eczema and pruritus. Compound Kushen Injection is a common dosage form of Kushen for clinical application, and the main component of Compound Kushen Injection is matrine. At present, Compound Kushen Injection has been put into clinical application in the adjuvant treatment of lung cancer (Wang et al., 2016), breast cancer (Ao et al., 2019), esophageal cancer (Zhang et al., 2018a), gastric cancer (Zhang et al., 2018b), colon cancer (Yu et al., 2017; Yang et al., 2018), liver cancer (Ma X. et al., 2016), and pancreatic cancer (Zhang et al., 2017). Compound Kushen injection is also used to relieve cancer-related pain (Guo et al., 2015). Matrine (molecular formula: $\mathrm{C}_{15} \mathrm{H}_{24} \mathrm{~N}_{2} \mathrm{O}$, molecular weight: $248.36 \mathrm{~g} / \mathrm{mol}$ ), a tetracyclo-quinolizindine alkaloid, is the main bioactive compound in Kushen, and more than 1 $\mathrm{g}$ of matrine can be extracted from $10 \mathrm{~kg}$ of Kushen (Lai et al., 2003; Liu X. J. et al., 2010). With the deepening of modern pharmacological research, the medicinal value of matrine has been further developed. At present, the basic researches on the antitumor and antiinflammatory effects of matrine are in a large volume, indicating that matrine has various pharmacological activities and potential for clinical application. In addition, matrine has a good prospect as a one-component drug in clinical practice, and single-component drugs have certain advantages over traditional Chinese 
medicine injections in quality control. In this paper, we summarized the pharmacological effects and mechanisms of matrine in order to provide reference for the follow-up study. Compared with the previous review of matrine (Rashid et al., 2019; Li et al., 2020), this paper makes comprehensive supplements of the pharmacological action and molecular mechanism of matrine.

\section{ANTICANCER ACTIVITY}

The antitumor activity of matrine is mainly manifested in inhibiting the proliferation of cancer cells, blocking cell cycle, inducing apoptosis and inhibiting the metastasis of cancer cells. At the same time, matrine can reverse the drug resistance of anticancer drugs and reduce the toxicity of anticancer drugs. The anticancer spectrum of matrine is very wide, and it can inhibit many kinds of cancer cells. The anticancer effect and mechanism of matrine are discussed in the following sections sorted by cancer types.

\section{Lung Cancer}

Lung cancer has the largest number of deaths among all cancers, and the 1-year survival rate of advanced patients is very low. There is always a great need for treatment in lung cancer (Blandin Knight et al., 2017). Matrine has a strong inhibitory effect on lung cancer cells. Matrine can block the cell cycle of lung cancer A549 cells in G1/G0 phase, upregulate the expression of microRNA (miR)-126, and then downregulate the expression of miR-126 target gene vascular endothelial growth factor (VEGF) and induce apoptosis (An et al., 2016). Matrine can also upregulate the expression of p53 and p21 and downregulate the expression levels of proliferating cell nuclear antigen (PCNA) and eukaryotic initiation factor $4 \mathrm{E}$ (eIF4E) to inhibit proliferation and migration (Lu et al., 2017). Matrine induces apoptosis in lung cancer cells, and also downregulates the expression of inhibitor of apoptosis protein (IAP) (Niu et al., 2014) and regulates the protein kinase $B / g l y c o g e n$ synthase kinase-3 $\beta$ (AKT/GSK-3 $\beta$ ) signaling pathway by regulating phosphatidylinositol 3-kinase (PI3K)/AKT/mammalian rapamycin target protein (mTOR) signaling pathway (Xie et al., 2018). For A549, NCI-H358 cells, matrine activates the p38 pathway by inducing reactive oxygen species (ROS) production, leading to caspase-dependent apoptosis, and inhibition of the p38 pathway by SB202190 partially prevents matrine-induced apoptosis (Tan et al., 2013). Matrine can also inhibit the proliferation and migration of lung cancer LA795 cells by regulating transmembrane protein 16A (TMEM16A), and inhibit the tumor growth of LA795 transplanted tumor mice (Guo et al., 2018a). Epithelial-mesenchymal transition (EMT) is closely related to tumor metastasis. Matrine can inhibit EMT and inhibit metastasis in nonsmall cell lung cancer by inhibiting the expression of paired box 2 (PAX2) (Yang J. et al., 2017). In the aspect of antilung cancer resistance, matrine can reverse the cisplatin-resistant lung cancer cells against apoptosis by regulating the $\beta$-catenin/survivin signaling pathway (Wang et al., 2015a). The development of epidermal growth factor receptor (EGFR) inhibitors is one of the difficulties in the treatment of lung cancer with EGFR mutation. Matrine treatment can reduce the expression of IL6, inhibit the activation of Janus tyrosine kinase/signal transducer and activator of transcription 3 (JAK1/STAT3) signaling pathway, decrease the expression of B-cell lymphoma-2 (Bcl2), inhibit cell growth, induce apoptosis, and enhance the inhibitory effect of afatinib on H1975 cells (Chen et al., 2017).

\section{Breast Cancer}

Shao et al. (2013) reported that matrine can inhibit the proliferation of breast cancer MCF7, BT-474, and MDA-MB231 cells, which may be related to the inhibition of inhibitory $\kappa \mathrm{B}$ kinase $\beta$ (IKK $\beta)$ regulation of nuclear factor $\kappa B(N F-\kappa B)$ signaling pathway. Matrine can induce endoplasmic reticulum stress in MCF-7 cells, downregulate the expression of hexokinase II, inhibit energy metabolism, promote apoptosis (Xiao et al., 2017), and reverse the drug resistance of MCF-7/ADR cells. Adriamycin (ADR) accumulates in cells and induces apoptosis in MCF-7/ADR cells by modulating the PI3K/AKT signaling pathway (Zhou B. G. et al., 2018). Matrine can also regulate Wnt/ $\beta$-catenin signaling pathway, inhibit the expression of VEGF, thereby inhibiting the proliferation of breast cancer 4T1, MCF-7 cells, inducing apoptosis, and inhibiting tumor growth in 4T1 tumor-bearing mice (Xiao et al., 2018).

\section{Liver Cancer}

Matrine can induce mitochondrial dysfunction in HepG2 cells, cause oxidative stress in cells, destroy cell energy metabolism, initiate endogenous apoptosis by regulating Mammalian STE20like protein kinase $1 / \mathrm{c}$-Jun NH2-terminal kinase (MST1/JNK) signaling pathway (Cao et al., 2019), and also inhibit mitosis through PINK1/PARKIN pathway, then promote apoptosis (Wei R. et al., 2018). Matrine is also capable of inducing caspase-independent programmed cell death via Bid-mediated AIF translocation (Zhou et al., 2014). Matrine can also induce autophagy in HepG2 cells and MHCC97L cells (Zhang et al., 2010; Yang and Yao, 2015). In hepatocellular carcinoma HepG2 cells, AMP-activated protein kinase (AMPK) signaling inhibits p53 and inhibits autophagy. After AMPK is inhibited, autophagy is converted to apoptosis (Xie et al., 2015). In addition, matrine has a proliferation inhibitory effect on cisplatin-purified liver cancer SMMC-7721 stem cell-like SMMC-7721-sphere cells (Wang H. et al., 2018). In addition, matrine can inhibit the migration and invasion of hepatoma cells by EMT via the Phosphatase and tensin homology deleted on chromosome ten (PTEN)/AKT pathway (Wang Z. et al., 2018). Matrine combined with resveratrol can better inhibit the proliferation of hepatoma cells and induce cell cycle arrest and endogenous apoptosis (Ou et al., 2014). When matrine combined with sorafenib, apoptosis 
of hepatocarcinoma cells can be induced by inhibiting miR-21 and upregulating PTEN expression (Lin et al., 2014).

\section{Cholangiocarcinoma/Gallbladder Carcinoma}

Matrine can induce choline cancer cell necrosis by increasing ROS production via the receptor-interacting protein 3/mixed lineage kinase domain like protein (Rip3/MLKL) pathway (Xu et al., 2017), and can also induce mitochondria-associated endogenous apoptosis in cholangiocarcinoma cells via the JAK2/STAT3 pathway (Yang et al., 2015). For gallbladder cancer cells, matrine can also inhibit proliferation and induce cell cycle arrest and apoptosis (Zhang et al., 2012).

\section{Pancreatic Cancer}

Pancreatic cancer is the lowest 5-year survival rate of all solid tumors and is expected to be the second leading cause of cancerrelated deaths in the United States by 2030 (Moffat and Epstein, 2019). Matrine can inhibit the proliferation and migration of pancreatic cancer Panc-1 cells, induce ROS production, and induce apoptosis, which is related to $\mathrm{ROS} / \mathrm{NF}-\kappa \mathrm{B} / \mathrm{matrix}$ metalloproteinase (MMP) pathway (Huang and Xin, 2018). Matrine can also inhibit the proliferation of KRAS-mutated pancreatic cancer MIAPACA2 and $8988 \mathrm{~T}$ cells, inhibit autophagy by downregulating STAT3, and inhibit mitochondrial energy production (Cho et al., 2018). Ma Y. et al. (2015) reported that matrine downregulates the expression of MT1-MMP via Wnt signaling pathway and inhibits pancreatic cancer cell migration and invasion. Matrine can inhibit the expression of PCNA and induce apoptosis in BxPC- 3 and Panc- 1 cells, and has no significant effect on human normal liver HL-7702 cells at the same dose. It can inhibit the growth of tumor xenograft tumors in vivo (Liu T. et al., 2010).

\section{Gastric Cancer}

Matrine can inhibit the proliferation and migration of gastric cancer SGC7901 cells by PI3K/AKT/uPA pathway (Peng et al., 2016). Matrine acts on gastric cancer SGC7901 cells, and miRNA screening revealed increased levels of eight miRNAs in the cell cycle pathway of target gene aggregation, while levels of 14 miRNAs in target mitogen-activated protein kinase (MAPK) signaling pathways were reduced (Li H. et al., 2014). Matrine can regulate the structure and subcellular distribution of vasodilatorstimulated phosphoprotein (VASP) in gastric cancer BGC823 cells, thereby inhibiting the adhesion and migration of cancer cells (Zhang et al., 2013). It has been reported that matrine can induce autophagy in gastric cancer SGC7901 cells, and at the same time, it can block the process of autophagy degradation by impairing the activity of lysosomal proteases, thus inducing death (Wang et al., 2013). However, studies have reported that matrine also induces protective autophagy, in which process matrine treatment does not directly inhibit the expression of $\mathrm{AKT}$ and its downstream effector $\mathrm{mTOR}$ and phosphorylation of p70 ribosomal protein S6 kinase (p70S6K), and inhibition of autophagy can enhance the killing of gastric cancer cells by matrine (Li et al., 2013).

\section{Colon Cancer}

Matrine can induce cell cycle arrest in G1/G0 phase and induce apoptosis in human colorectal cancer cell lines LS174T, Caco-2, SW1116, and Rko. Compared with oxaliplatin, matrine The LS174T nude mouse xenograft model has less influence on physical strength and body weight (Gu et al., 2018). Matrine can inhibit tumor growth in rats with colorectal cancer model, which is associated with inhibition of high mobility group protein box 1 (HMGB1) signaling pathway (Fan et al., 2018). For both LoVo cells and HT29 cells, matrine can also induce apoptosis (Chang et al., 2013; Zhang et al., 2014).

\section{Prostate Cancer}

Li et al. (2018) used the Hiseq 2500 high-throughput sequencing platform to screen the proliferation inhibition mechanism of matrine on prostate cancer PC-3 and DU145 cells. The results showed that matrine inhibited cell proliferation, migration, and invasion through Forkhead box protein $\mathrm{O}$ (FoxO) and PI3K/ AKT signaling pathways. Induction of apoptosis. Studies have shown that matrine upregulates gadd45b expression via $\mathrm{p} 38$ / JNK, ROS/gadd45b/p38 pathway, inhibits proliferation and migration of prostate cancer DU145, PC3 cells, and induces apoptosis (Huang et al., 2018), which is also associated with NF$\kappa \mathrm{B}$ pathway (Li Q. et al., 2016). Matrine can inhibit the proteasome CTLIKE activity by activating the unfolded protein response/endoplasmic reticulum (UPR/ER) pathway, arresting the cell cycle in the G0/G1 phase, inducing apoptosis of prostate cancer cells, and inhibiting tumor growth in vivo (Chang et al., 2018). The inhibition of matrine on PC-3 cells is also associated with the regulation of Bim and p27 expression (Bai et al., 2017). However, studies have shown that matrine can inhibit tumor growth in DU145 xenograft model mice, but it is not effective in PC-3 xenograft model mice (Huang et al., 2017).

\section{Osteosarcoma}

Matrine can induce apoptosis in human osteosarcoma MG-63 cells, but it also induces protective autophagy in MG-63 cells through extracellular signal-regulated kinase (ERK) signaling pathway, and inhibition of autophagy with chloroquine can enhance killing ( $\mathrm{Ma} \mathrm{K}$. et al., 2016). Matrine also inhibits osteosarcoma cell proliferation and migration via the ERK/NFkappaB signaling pathway (Li Y. et al., 2014). Matrine can also inhibit the growth of MNNG/HOS xenografts in vivo (Liang et al., 2012).

\section{Leukemia}

Matrine can inhibit the expression of hsa-mir-106 b-3p and upregulate the expression of CDKN1A in human acute lymphoblastic leukemia (ALL) cell line CCRF-CEM, thereby blocking the cell cycle at G0/G1 phase and inducing apoptosis (Tetik et al., 2018). Matrine can increase the production of ROS in human acute lymphoblastic leukemia B cells, leading to mitochondrial swelling and mitochondrial membrane potential decline, thus inducing apoptosis (Aghvami et al., 2018). Matrine can also inhibit the proliferation of AML cells by inducing apoptosis and autophagy, and inhibit the phosphorylation of 
AKT, mTOR, and their downstream substrates p70S6K and eukaryotic translation initiation factor $4 \mathrm{E}$ binding protein 1 (eIF4EBP1) (Wu J. et al., 2017). Matrine can also upregulate the expression of NKG2D ligand (NKG2DL) in leukemia cell lines and primary leukemia cells, and enhance the killing effect of NK and CIK cells on leukemia K562 cells (Zhang L. et al., 2015). The killing effect of Matrine on K562 cells is also related to interleukin-6 (IL-6)/JAK/STAT3 pathway (Ma L. et al., 2015).

\section{Other Cancers}

Matrine can effectively inhibit the growth of glioblastoma multiforme (GBM) cells in vitro by inducing cell senescence, and downregulate the expression of insulin-like growth factor (IGF1), PI3K, and p-AKT. In an orthotopic xenograft model established by u251 and p3 cells transfected with luciferase, matrine inhibited tumor growth, and prolonged the overall survival of the animal model (Zhou W. et al., 2018). In addition, matrine can inhibit glioma cell metastasis and EMT, accompanied by inhibition of p38 MAPK and AKT signaling pathways (Wang et al., 2015b).

Matrine can induce mitochondrial-related endogenous apoptosis in retinoblastoma cells (Shao et al., 2014).

Matrine can regulate NF- $\kappa B$ to inhibit the migration and invasion of nasopharyngeal carcinoma cells (Sun and Xu, 2015).

Matrine can inhibit the proliferation of esophageal cancer Kyse-150 cells, induce ROS production and induce apoptosis. Matrine can destroy F-actin and nuclear structure. Morphological observation showed that the roughness and surface height of cell membrane increased with the increase of drug concentration (Jiang et al., 2018). Wang et al. (2014) reported that matrine acted on Eca-109 cells, induced apoptosis by upregulating p53 and p21, and arrested cell cycle in $\mathrm{G} 0 / \mathrm{G} 1$ phase.

Matrine can significantly inhibit the proliferation and migration of cervical cancer cells by inhibiting p38 signaling pathway and inducing apoptosis (Wu X. et al., 2017).

Cisplatin is one of the first-line drugs for the treatment of urothelial bladder cancer (UBC), but its side effects and drug resistance become the limitations of its application. When the ratio of matrine to cisplatin was 2,000:1, it could synergistically inhibit UBC cells. The combination of the two drugs can inhibit the proliferation, invasion and EMT of UBC cells, induce cell cycle arrest and apoptosis, which is related to the signal pathway of VEGF/PI3K/AKT (Liao et al., 2017).

Matrine can inhibit the proliferation of rhabdomyosarcoma cells by inhibiting ERK signaling pathway and induce apoptosis (Yan et al., 2017). In combination with cisplatin, matrine can downregulate the expression of X-linked IAP (XIAP) and induce the apoptosis of rhabdomyosarcoma RD cells (Li L. et al., 2016).

Matrine combined with CYC116 can inhibit the proliferation of multiple myeloma RPMI8226 cells and induce apoptosis through PI3K/AKT pathway (Zhou et al., 2015).

It has been reported that matrine can inhibit the expression of miR-19b-3p and then upregulate PTEN, inhibit the proliferation and invasion of human A375 and SK-MEL-2 melanoma cell lines, and induce apoptosis (Wei Y. et al., 2018). Matrine can also upregulate PTEN expression and induce apoptosis in M21 cells (Jin et al., 2013).

Antitumor related studies of matrine are summarized in Table 1, and the mechanisms of actions are summarized in Figure 1.

\section{NONANTICANCER ACTIVITIES}

Matrine has therapeutic effects on Alzheimer's syndrome, encephalomyelitis, asthma, myocardial ischemia, rheumatoid arthritis (RA), and osteoporosis in vitro and in vivo. The spectrum of treatable diseases extends to many systems, such as nervous system, circulatory system, immune system and so on. Its mechanism is mainly to inhibit inflammation, reduce oxidative stress, regulate autophagy and apoptosis, etc. The antidisease effects and mechanisms of matrine are discussed in human body system and disease subsection below.

\section{Neurological Diseases \\ Alzheimer's Syndrome}

It is estimated that 24 million people worldwide suffer from dementia, most of whom are thought to have Alzheimer's disease (AD). Therefore, $\mathrm{AD}$ is a major public health problem and a recognized research focus. Innovative therapies are urgently needed to cure or alleviate the disease (Ballard et al., 2011). Matrine has the potential to treat Alzheimer's syndrome. Matrine can inhibit the cytotoxicity induced by $A \beta 42$, inhibit the $A \beta /$ RAGE signaling pathway in vitro. Matrine reduces the deposition of proinflammatory cytokines and $\mathrm{A} \beta$ in $\mathrm{AD}$ transgenic mice and reduces memory deficit (Cui et al., 2017). It has been reported that matrine can reverse the changes of Th17/Treg cytokines induced by $\mathrm{A} \beta 42$ injection in $\mathrm{AD}$ rats, downregulate the expression of retinoid-related orphan receptor $\gamma \mathrm{t}$ (ROR $\gamma \mathrm{t}$ ), upregulate the expression of fork head box p3 (Foxp3), a specific transcription factor of Th17 cells, improve the learning and memory abilities of $\mathrm{AD}$ rats, and alleviate the cognitive impairment of AD rats (Zhang Y. et al., 2015).

\section{Cerebral Ischemia}

Matrine can alleviate cerebral ischemic injury, reduce the level of malondialdehyde (MDA), upregulate the expression of superoxide dismutase (SOD), glutathione peroxidase (GSH$\mathrm{px})$, catalase (CAT), and inhibit the apoptosis of ischemic neurons (Zhao et al., 2015).

\section{Spinal Cord Injury/Encephalomyelitis}

Matrine can promote axon growth and functional recovery in spinal cord injury (SCI) mice. Through drug affinity response target stability (DARTS) system screening, Matrine can directly bind heat shock protein 90 (HSP90), through neutralization. Specific blockade of anti-HSP90 by antibody can inhibit the growth of axons induced by matrine, suggesting that the improvement of SCI by matrine depends on the regulation of HSP90 (Tanabe et al., 2018). Matrine can also upregulate the expression of protein lipid protein, increase the number of 
TABLE 1 | Antitumor studies of matrine.

\begin{tabular}{|c|c|c|c|c|}
\hline Diseases & Models & Effects & Mechanisms & References \\
\hline \multirow[t]{8}{*}{ Lung cancer } & A549 cells & $\begin{array}{l}\text { Apoptosis } \uparrow \text {, proliferation } \downarrow \text {, } \\
\text { cell cycle arrest }\end{array}$ & $\operatorname{miR}-126 \uparrow, V E G F \downarrow$ & (An et al., 2016) \\
\hline & & $\begin{array}{l}\text { Apoptosis } \uparrow \text {, proliferation } \downarrow \text {, } \\
\text { migration } \downarrow\end{array}$ & $\mathrm{p} 53 \uparrow, \mathrm{p} 21 \uparrow, \mathrm{PCNA} \downarrow, \mathrm{elF} 4 \mathrm{E} \downarrow$ & (Lu et al., 2017) \\
\hline & A549, 95D cells & Apoptosis $\uparrow$, proliferation $\downarrow$ & clAP $\downarrow, p-A K T \downarrow$ & (Niu et al., 2014) \\
\hline & A549, NCl-H358 cells & $\begin{array}{l}\text { ROS generation } \uparrow, \\
\text { apoptosis } \uparrow \text {, proliferation } \downarrow\end{array}$ & $\begin{array}{l}\text { Cleaved caspase } 3 \uparrow \text {, cleaved PARP } \uparrow, \text { bcl- } 2 \downarrow \text {, bad } \uparrow, p- \\
\text { p38 } \uparrow\end{array}$ & (Tan et al., 2013) \\
\hline & A549, H1299 cells & $\begin{array}{l}\text { Apoptosis } \uparrow \text {, proliferation } \downarrow \text {, } \\
\text { migration } \downarrow\end{array}$ & $\mathrm{p}-\mathrm{AKT} \downarrow, \mathrm{p}-\mathrm{GSK} 3 \beta \downarrow$ & (Xie et al., 2018) \\
\hline & $\begin{array}{l}\text { LA795 cells; LA795 tumor bearing } \\
\text { BALB/c mice }\end{array}$ & $\begin{array}{l}\text { Proliferation } \downarrow \text {, migration } \downarrow \text {, } \\
\text { tumor volume } \downarrow\end{array}$ & TMEM16A $\downarrow$ & (Guo et al., 2018a) \\
\hline & A549, H1299 cells & $\begin{array}{l}\text { Proliferation } \downarrow \text {, migration } \downarrow \text {, } \\
\text { EMT } \downarrow\end{array}$ & PAX2 $\downarrow, N$-cadherin $\downarrow$, E-cadherin $\uparrow$, MMP2 $2 \downarrow$, MMP9 $\downarrow$ & $\begin{array}{l}\text { (Yang J. et al., } \\
\text { 2017) }\end{array}$ \\
\hline & A549, H460 cells & Apoptosis $\uparrow$, proliferation $\downarrow$ & $\begin{array}{l}\text { p-GSK3 } \beta \downarrow \text {, p- } \beta \text {-catenin } \downarrow \text {, survivin } \downarrow \text {, caspase } 3 \uparrow, \\
\text { caspase } 9 \uparrow\end{array}$ & $\begin{array}{l}\text { (Wang et al., } \\
\text { 2015a) }\end{array}$ \\
\hline $\begin{array}{l}\text { Lung cancer } \\
\text { (Matrine\&afatinib) }\end{array}$ & $\begin{array}{l}\text { H1975 cells; H1975 tumor bearing } \\
\text { male BALB/c nude mice }\end{array}$ & $\begin{array}{l}\text { Apoptosis } \uparrow \text {, proliferation } \downarrow \text {, } \\
\text { tumor volume } \downarrow\end{array}$ & 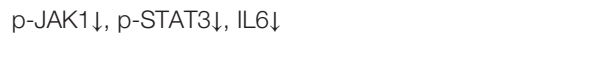 & (Chen et al., 2017) \\
\hline \multirow[t]{4}{*}{ Breast cancer } & MCF-7, BT-474, MDA-MB-231 cells & Proliferation $\downarrow$ & $\mid \mathrm{KK} \beta \downarrow$ & (Shao et al., 2013) \\
\hline & MCF-7 cells & Apoptosis $\uparrow$, proliferation $\downarrow$, & GRP78 $\uparrow$, elF2 $\alpha \uparrow, \mathrm{CHOP} \uparrow$, cyto-cyt-C $\uparrow$, hexokinase $I I \downarrow$ & (Xiao et al., 2017) \\
\hline & $\begin{array}{l}\text { 4T1, MCF-7 cells; 4T1 tumor bearing } \\
\text { BALB/c mice }\end{array}$ & $\begin{array}{l}\text { Apoptosis } \uparrow \text {, proliferation } \downarrow \text {, } \\
\text { tumor volume } \downarrow\end{array}$ & 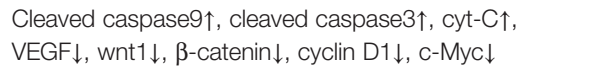 & (Xiao et al., 2018) \\
\hline & MCF-7/ADR cells & $\begin{array}{l}\text { Apoptosis } \uparrow \text {, proliferation } \downarrow \text {, } \\
\text { intracellular concentration } \\
\text { of ADR } \uparrow\end{array}$ & $\begin{array}{l}\text { p-gp } \downarrow, \text { MRP } 1 \downarrow, p-A K T \downarrow, \text { bcl- } 2 \downarrow, \text { PTEN } \uparrow, \text { bax } \uparrow \text {, cleaved } \\
\text { caspase-3 } \uparrow\end{array}$ & $\begin{array}{l}\text { (Zhou B. G. et al., } \\
\text { 2018) }\end{array}$ \\
\hline \multirow[t]{8}{*}{ Liver cancer } & HepG2, Huh7 cells & $\begin{array}{l}\text { Apoptosis } \uparrow \text {, viability } \downarrow \text {, } \\
\text { migration } \downarrow \text {,proliferation } \downarrow \text {, } \\
\text { mitochondrial fission } \uparrow, \\
\text { cellular oxidative stress } \uparrow\end{array}$ & 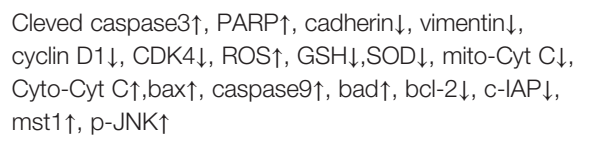 & (Cao et al., 2019) \\
\hline & HepG2 cells & $\begin{array}{l}\text { Apoptosis } \uparrow \text {, proliferation } \downarrow \text {, } \\
\text { migration } \downarrow \text {, mitophagy } \downarrow\end{array}$ & $\begin{array}{l}\text { Cleaved caspase } 3 \uparrow, \text { PARP } \uparrow \text {, cadherin } \downarrow \text {, vimentin } \downarrow \text {, } \\
\text { cyclin D1 } \downarrow \text {, CDK } 4 \downarrow \text {, mito-Cyt C } \downarrow \text {, cyto-Cyt C } \uparrow, \text { bax } \uparrow, \\
\text { caspase } 9 \uparrow, \text { bcl- } 2 \downarrow, \text { CIII-core } 2 \downarrow, \text { CII-30 } \downarrow \text {, CIV-II } \downarrow \text {, LC3- } \\
\text { II, Atg5 } \downarrow \text {, vps34 } \downarrow \text {, PINK } 1 \downarrow, \text { PARKIN } \downarrow\end{array}$ & (Wei R. et al., 2018) \\
\hline & $\begin{array}{l}\text { HepG2 cells; HepG2 tumor bearing } \\
\text { female BALB/c nude mice }\end{array}$ & $\begin{array}{l}\text { Apoptosis } \uparrow \text {, proliferation } \downarrow \text {, } \\
\text { tumor volume } \downarrow\end{array}$ & $\begin{array}{l}\text { Mito-cyt-C } \downarrow \text {, cyto-cyt-C } \uparrow, \mathrm{HSP} 60 \uparrow, \text { fas } \uparrow \text {, fasL } \uparrow \text {, mito- } \\
\text { AIF } \downarrow \text {, cyto-AIF } \uparrow, \text { nuc-AIF } \uparrow\end{array}$ & (Zhou et al., 2014) \\
\hline & HepG2 cells & $\begin{array}{l}\text { Apoptosis } \uparrow \text {, proliferation } \downarrow \text {, } \\
\text { autophagy } \uparrow\end{array}$ & Bax $\uparrow$, beclin $1 \uparrow$ & (Zhang et al., 2010) \\
\hline & $\begin{array}{l}\text { MHCC97L, Huh- } 7 \text { cells; MHCC97L } \\
\text { tumor bearing male BALB/c nude } \\
\text { mice }\end{array}$ & $\begin{array}{l}\text { Apoptosis } \uparrow \text {, autophagy } \uparrow \text {, } \\
\text { proliferation } \downarrow \text {, }\end{array}$ & 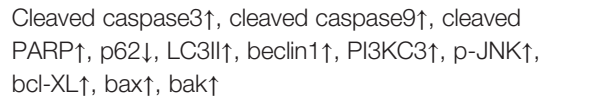 & $\begin{array}{l}\text { (Yang and Yao, } \\
\text { 2015) }\end{array}$ \\
\hline & HepG2, SMMC7721 cells & $\begin{array}{l}\text { Apoptosis } \uparrow \text {, proliferation } \downarrow \text {, } \\
\text { autophagy } \uparrow\end{array}$ & 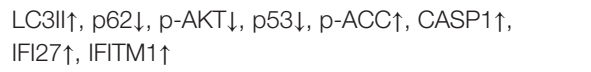 & (Xie et al., 2015) \\
\hline & SMMC-7721-sphere cells & Proliferation $\downarrow$ & $\mathrm{CAR} \uparrow, \mathrm{E}-$-cadherin $\uparrow$, laminin $\uparrow$, fibronectin $\uparrow$ & $\begin{array}{l}\text { (Wang H. et al., } \\
\text { 2018) }\end{array}$ \\
\hline & Huh-7 cells & $\begin{array}{l}\text { Proliferation } \downarrow \text {, migration } \downarrow \text {, } \\
\text { EMT } \downarrow\end{array}$ & $\begin{array}{l}\text { Cadherin } \downarrow \text {, vimentin } \downarrow \text {, Slug } \downarrow \text {,Snail } \downarrow, \text { MMP2 } \downarrow \text {, MMP } 9 \downarrow \text {, } \\
\text { PTEN } \uparrow, p-A K T \downarrow\end{array}$ & $\begin{array}{l}\text { (Wang Z. et al., } \\
\text { 2018) }\end{array}$ \\
\hline $\begin{array}{l}\text { Liver cancer } \\
\text { (Matrine\&resveratrol) }\end{array}$ & HepG2 cells & $\begin{array}{l}\text { Apoptosis } \uparrow \text {, proliferation } \downarrow \text {, } \\
\text { ROS generation } \uparrow\end{array}$ & Survivin $\downarrow, \mathrm{PARP} \uparrow, \mathrm{bax} \uparrow, \mathrm{bcl}-2 \downarrow$ & (Ou et al., 2014) \\
\hline $\begin{array}{l}\text { Liver cancer } \\
\text { (Matrine\&sorafenib) }\end{array}$ & HepG2, Hep3B cells & Apoptosis $\uparrow$, proliferation $\downarrow$ & Cleaved caspase $3 \uparrow$, cleaved PARP $\uparrow, \mathrm{PTEN} \uparrow$, miR-21 $\downarrow$ & (Lin et al., 2014) \\
\hline \multirow[t]{2}{*}{ Cholangiocarcinoma } & Mz-ChA-1, QBC939 cells & $\begin{array}{l}\text { Necrosis } \uparrow \text {, proliferation } \downarrow \text {, } \\
\text { ROS generation } \uparrow\end{array}$ & $\mathrm{RIP} 3 \uparrow$ & (Xu et al., 2017) \\
\hline & Mz-ChA-1, KMCH-1 cells & Apoptosis $\uparrow$, proliferation $\downarrow$ & $\begin{array}{l}\text { Mito-cyto-C } \downarrow \text {, cyto-cyto-C } \uparrow \text {, caspase } 9 \uparrow \text {, caspase } 3 \uparrow \text {, } \\
\text { p-JAK2 } \downarrow, \text { p-STAT3 } \downarrow, \text { Mcl- } 1 \downarrow\end{array}$ & (Yang et al., 2015) \\
\hline $\begin{array}{l}\text { Gallbladder } \\
\text { carcinoma }\end{array}$ & GBC-SD cells & $\begin{array}{l}\text { Apoptosis } \uparrow \text {, proliferation } \downarrow \text {, } \\
\text { cell cycle arrest }\end{array}$ & cleaved caspase $3 \uparrow$, bax $\uparrow$, bcl- $2 \downarrow$, cyclin $E \downarrow$ & (Zhang et al., 2012) \\
\hline \multirow[t]{2}{*}{ Pancreatic cancer } & Panc-1 cells & $\begin{array}{l}\text { Apoptosis } \uparrow \text {, proliferation } \downarrow \text {, } \\
\text { migration } \downarrow \text {, EMT } \downarrow \text {, cell } \\
\text { cycle arrest, ROS } \\
\text { generation } \uparrow\end{array}$ & $\begin{array}{l}\text { MMP-9 } \downarrow, \text { MMP- } 2 \downarrow, \text { E-cadherin } \downarrow, N \text {-cadherin } \downarrow \text {, } \\
\text { vimentin } \downarrow, p-\mid \kappa B \alpha \downarrow, p-p 65 \downarrow \text {, }\end{array}$ & $\begin{array}{l}\text { (Huang and Xin, } \\
\text { 2018) }\end{array}$ \\
\hline & $\begin{array}{l}\text { MIAPACA2, 8988T cells; } 8988 T \\
\text { tumor bearing female SCID mice }\end{array}$ & $\begin{array}{l}\text { Proliferation } \downarrow \text {, autophagic } \\
\text { degradation } \downarrow \text {, tumor } \\
\text { volume } \downarrow\end{array}$ & p-STAT3 $\downarrow$, p62^ & (Cho et al., 2018) \\
\hline
\end{tabular}


TABLE 1 | Continued

\begin{tabular}{|c|c|c|c|c|}
\hline Diseases & Models & Effects & Mechanisms & References \\
\hline & HPAC, Capan-1 cells & Proliferation $\downarrow$, migration $\downarrow$ & MTI-MMP $\downarrow, M M P-2 \downarrow, M M P-9 \downarrow, W n t \downarrow, \beta$-catenin $\downarrow$ & (Ma Y. et al., 2015) \\
\hline & $\begin{array}{l}\text { BxPC-3, Panc- } 1 \text { cells; BxPC-3 tumor } \\
\text { bearing male nude BALB/c mice }\end{array}$ & $\begin{array}{l}\text { Apoptosis } \uparrow \text {, proliferation } \downarrow \text {, } \\
\text { tumor volume } \downarrow\end{array}$ & $\begin{array}{l}\text { PCNA } \downarrow \text {, cleaved caspase } 3 \uparrow, \text { cleaved caspase } 9 \uparrow, \\
\text { cleaved caspase } \$ \uparrow, \text { bax } \uparrow, \text { bcl- } 2 \downarrow \text {, fas } \uparrow\end{array}$ & (Liu T. et al., 2010) \\
\hline \multirow[t]{5}{*}{ gastric cancer } & SGC7901 cells & Proliferation $\downarrow$, migration $\downarrow$ & $p-E R K \downarrow, p-A K T \downarrow, u P A \downarrow$ & (Peng et al., 2016) \\
\hline & SGC-7901 cells & Proliferation $\downarrow$ & $\begin{array}{l}\text { Regulating cell cycle, MAPK signaling pathway related } \\
\text { miRNAs }\end{array}$ & (Li H. et al., 2014) \\
\hline & BGC823 cells & Proliferation $\downarrow$, migration $\downarrow$ & $p-V A S P \downarrow, V A S P \downarrow$ & (Zhang et al., 2013) \\
\hline & SGC7901, BGC823 cells & $\begin{array}{l}\text { Autophagy induction } \uparrow, \\
\text { autophagic degradation } \downarrow\end{array}$ & LC3-II $\uparrow$, p62 $\uparrow$, procathepsin $\uparrow$ & (Wang et al., 2013) \\
\hline & SGC7901 cells & $\begin{array}{l}\text { Apoptosis } \uparrow \text {, proliferation } \downarrow \text {, } \\
\text { autophagy } \uparrow\end{array}$ & $\mathrm{p}-\mathrm{AKT} \uparrow, \mathrm{p}-\mathrm{mTOR} \uparrow, \mathrm{p}-\mathrm{P} 70 \mathrm{~S} 6 \mathrm{~K} \uparrow$ & (Li et al., 2013) \\
\hline \multirow[t]{4}{*}{ Colon cancer } & $\begin{array}{l}\text { LS174T, Caco-2, SW1116, RKO } \\
\text { cells; LS174T tumor bearing BALB/c } \\
\text { male nude mice }\end{array}$ & $\begin{array}{l}\text { Apoptosis } \uparrow \text {, proliferation } \downarrow \text {, } \\
\text { cell cycle arrest, tumor } \\
\text { volume } \downarrow \text {, tumor weight } \downarrow\end{array}$ & Bcl-2 $\downarrow$, bax $\uparrow$, cleaved caspase $\downarrow$ & (Gu et al., 2018) \\
\hline & $\begin{array}{l}\text { 1,2-dimethylhydrazine } \\
\text { dihydrochloride treated male } \\
\text { WISTAR rats }\end{array}$ & Tumor volume $\downarrow$ & HMGB1 $\downarrow, \mid L-6 \downarrow$, TNF- $\alpha \downarrow$ & (Fan et al., 2018) \\
\hline & LoVo cells & Apoptosis $\uparrow$, proliferation $\downarrow$ & 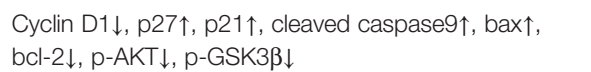 & (Zhang et al., 2014) \\
\hline & HT29 cells & $\begin{array}{l}\text { apoptosis } \uparrow, \text { proliferation } \downarrow \text {, } \\
\text { cell cycle arrest }\end{array}$ & $\begin{array}{l}\text { cleaved caspase } 3 \uparrow \text {, cleaved caspase } 9 \uparrow, \text { bax } \uparrow, \text { bcl- } 2 \downarrow \text {, } \\
\text { mito-cyt-C } \downarrow \text {, cyto-cyt-C } \uparrow\end{array}$ & (Chang et al., 2013) \\
\hline \multirow[t]{6}{*}{ Prostate cancer } & DU145, PC-3 cells & $\begin{array}{l}\text { Apoptosis } \uparrow \text {, proliferation } \downarrow \text {, } \\
\text { migration } \downarrow\end{array}$ & 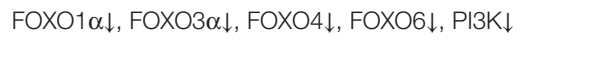 & (Li et al., 2018) \\
\hline & DU145, PC3 cells & $\begin{array}{l}\text { Apoptosis } \uparrow \text {, proliferation } \downarrow \text {, } \\
\text { migration } \downarrow\end{array}$ & Gadd45b个 & (Huang et al., 2018) \\
\hline & $\begin{array}{l}\text { DU145, PC3 cells; DU145 tumor } \\
\text { bearing male BALB/c nude mice }\end{array}$ & $\begin{array}{l}\text { Apoptosis } \uparrow \text {, proliferation } \downarrow \text {, } \\
\text { migration } \downarrow \text {, cell cycle } \\
\text { arrest, EMT } \downarrow\end{array}$ & $\begin{array}{l}\text { E-cadherin } \uparrow, N \text {-cadherin } \downarrow \text {, vimentin } \downarrow \text {, p-elF2 } \alpha \uparrow \text {, } \\
\text { ATF4 } \uparrow, \mathrm{CHOP} \uparrow, \mathrm{c}-\mathrm{myc} \downarrow \text {, bcl- } 2 \downarrow \text {, bak } \uparrow \text {, cleaved } \\
\text { PARP } \uparrow\end{array}$ & (Chang et al., 2018) \\
\hline & $\begin{array}{l}\text { DU145, PC-3 cells; DU145, PC-3 } \\
\text { tumor bearing male BALB/c nude } \\
\text { mice }\end{array}$ & $\begin{array}{l}\text { Proliferation } \downarrow \text {, migration } \downarrow \text {, } \\
\text { tumor volume in DU145 } \\
\text { tumor bearing mice } \downarrow\end{array}$ & p-MMP2 $\downarrow$, p-MMP9 $\downarrow, p-p 65 \downarrow$ & (Huang et al., 2017) \\
\hline & $\begin{array}{l}\text { PC-3 cells; Prostate epithelial cells } \\
\text { RWPE1 }\end{array}$ & $\begin{array}{l}\text { Apoptosis } \uparrow \text {, proliferation } \downarrow \text {, } \\
\text { cell cycle arrest }\end{array}$ & $\begin{array}{l}\mathrm{p} 27 \uparrow, \mathrm{CDK} 4 \downarrow, \mathrm{CDK} 2 \downarrow, \mathrm{bax} \uparrow, \mathrm{bim} \uparrow, \mathrm{bcl}-2 \downarrow, \mathrm{p}-\mathrm{AK} T \downarrow, \mathrm{p}- \\
\mathrm{FOXO} 3 \alpha \downarrow\end{array}$ & (Bai et al., 2017) \\
\hline & DU145, PC-3 cells & $\begin{array}{l}\text { Apoptosis } \uparrow \text {, proliferation } \downarrow \text {, } \\
\text { cell cycle arrest }\end{array}$ & $p-p 65 \downarrow, p-|K K \alpha / \beta \downarrow, p-| \kappa B \alpha \downarrow$ & (Li Q. et al., 2016) \\
\hline \multirow[t]{3}{*}{ Osteosarcoma } & MG-63 cells & $\begin{array}{l}\text { Apoptosis } \uparrow \text {, proliferation } \downarrow \text {, } \\
\text { autophagy } \uparrow\end{array}$ & $\mathrm{p}-\mathrm{ERK} \uparrow, \mathrm{LC} 3-\| \uparrow, \operatorname{bax} \uparrow$ & (Ma K. et al., 2016) \\
\hline & $\begin{array}{l}\text { SaOS-2, U2OS, MG-63 cells; U2OS } \\
\text { tumor bearing male BALB/c nude } \\
\text { mice }\end{array}$ & Proliferation $\downarrow$, migration $\downarrow$, & MMP-2 $\downarrow$, MMP-9 $\downarrow, p 65 \downarrow, p 50 \downarrow, \mid \kappa B-\beta \downarrow, p-E R K \downarrow$ & (Li Y. et al., 2014) \\
\hline & $\begin{array}{l}\text { MG-63, U-2OS, Saos-2, MNNG/ } \\
\text { HOS cells; MNNG/HOS tumor } \\
\text { bearing female BALB/c mice }\end{array}$ & $\begin{array}{l}\text { Apoptosis } \uparrow \text {, proliferation } \downarrow \text {, } \\
\text { tumor volume } \downarrow\end{array}$ & $\begin{array}{l}\text { Cleaved caspase } 3 \uparrow, \text { cleaved caspase } 9 \uparrow \text {, cleaved } \\
\text { caspase } 8 \uparrow, \text { fas } \uparrow, \text { fas } L \uparrow, \text { bax } \uparrow, \text { bcl- } 2 \downarrow\end{array}$ & (Liang et al., 2012) \\
\hline \multirow[t]{5}{*}{ Leukemia } & CCRF-CEM cells & $\begin{array}{l}\text { Cell cycle arrest, } \\
\text { apoptosis } \uparrow, \text { proliferation } \downarrow\end{array}$ & 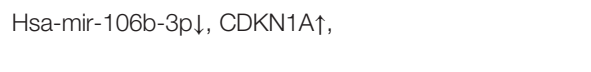 & (Tetik et al., 2018) \\
\hline & human ALL B-lymphocytes & Apoptosis $\uparrow$, proliferation $\downarrow$ & $\mathrm{Bax} \uparrow, \mathrm{bcl}-2 \downarrow$ & $\begin{array}{l}\text { (Aghvami et al., } \\
\text { 2018) }\end{array}$ \\
\hline & $\begin{array}{l}\text { HL-60, THP-1, C1498 cells; C1498 } \\
\text { tumor bearing C57BL/6 mice }\end{array}$ & $\begin{array}{l}\text { Apoptosis } \uparrow \text {, proliferation } \downarrow \text {, } \\
\text { autophagy } \uparrow \text {, cell cycle } \\
\text { arrest, spleen weight } \downarrow \text {, } \\
\text { survival } \uparrow\end{array}$ & $\begin{array}{l}\text { p62 } \downarrow \text {, LC3-II } \uparrow, P A R P \uparrow, \text { cleaved caspase } 3 \uparrow, p-A K T \downarrow, p- \\
\text { mTOR } \downarrow\end{array}$ & (Wu J. et al., 2017) \\
\hline & $\begin{array}{l}\text { K562, OUN-1, HL-60, U937, } \\
\text { K562/AO2 cells }\end{array}$ & NK and CIK cytotoxicity $\uparrow$ & $\begin{array}{l}\text { NKG2DL } \uparrow, \| L-6, I L-1, I L-2, I L-4, I L-5, \text { GRO and TNF- } \\
\alpha \downarrow, \text { CD158a } \downarrow, C D 158 b \downarrow\end{array}$ & $\begin{array}{l}\text { (Zhang L. et al., } \\
\text { 2015) }\end{array}$ \\
\hline & K562 cells & $\begin{array}{l}\text { Apoptosis } \uparrow \text {, proliferation } \downarrow \text {, } \\
\text { cell cycle arrest }\end{array}$ & $\begin{array}{l}\text { Bcl-XL } \downarrow \text {, cyclin D } \downarrow, c-m y c \downarrow \text {, p-JAK2 } \downarrow \text {, p-STAT3 } \downarrow, I L- \\
6 \downarrow\end{array}$ & (Ma L. et al., 2015) \\
\hline Glioma & $\begin{array}{l}\text { human glioma cell lines (U251, TCHu } \\
\text { 58, U87MG, TCHu138); GFP- } \\
\text { luciferase- stable U251 and P3 } \\
\text { glioma cells bearing athymic mice }\end{array}$ & $\begin{array}{l}\text { Proliferation } \downarrow \text {, cell cycle } \\
\text { arrest, induce cellular } \\
\text { senescence, tumor } \\
\text { growth } \downarrow \text {, animal model } \\
\text { survival } \uparrow\end{array}$ & $|\mathrm{GF} 1 \downarrow, \mathrm{PI}| \mathrm{K} \downarrow, \mathrm{p}-\mathrm{AKT} \downarrow$ & $\begin{array}{l}\text { (Zhou W. et al., } \\
\text { 2018) }\end{array}$ \\
\hline
\end{tabular}


TABLE 1 | Continued

\begin{tabular}{|c|c|c|c|c|}
\hline Diseases & Models & Effects & Mechanisms & References \\
\hline & U251MG, U87MG cells & $\begin{array}{l}\text { Proliferation } \downarrow \text {, migration } \downarrow \text {, } \\
\text { EMT } \downarrow\end{array}$ & E-cadherin $\uparrow, N$-cadherin $\downarrow, p-p 38 \downarrow, p-A K T \downarrow$, & $\begin{array}{l}\text { (Wang et al., } \\
\text { 2015b) }\end{array}$ \\
\hline Retinoblastoma & SO-Rb50 cells & Apoptosis $\uparrow$, proliferation $\downarrow$ & $\begin{array}{l}\text { Apaf- } 1 \uparrow \text {, cleaved caspase } 3 \uparrow \text {, cleaved caspase } 9 \uparrow \text {, } \\
\text { cleaved caspase } 7 \uparrow, \text { bax } \uparrow, \text { bcl- } 2 \downarrow\end{array}$ & (Shao et al., 2014) \\
\hline $\begin{array}{l}\text { Nasopharyngeal } \\
\text { carcinoma }\end{array}$ & $\begin{array}{l}\text { NPC-039, CNE-2Z cells; NPC-039 } \\
\text { tumor bearing BALB/c nude mice }\end{array}$ & $\begin{array}{l}\text { Proliferation } \downarrow \text {, migration } \downarrow \text {, } \\
\text { tumor volume } \downarrow\end{array}$ & MMP- $2 \downarrow, \mathrm{MMP}-9 \downarrow, \mathrm{p} 50 \downarrow, \mathrm{p} 65 \downarrow$ & (Sun and $\mathrm{Xu}, 2015$ ) \\
\hline \multirow[t]{2}{*}{ Esophageal cancer } & Kyse-150 cells & $\begin{array}{l}\text { Apoptosis } \uparrow \text {, proliferation } \downarrow \text {, } \\
\text { migration } \downarrow \text {, ROS } \\
\text { generation } \uparrow\end{array}$ & $\begin{array}{l}\text { Bax } \uparrow \text {, caspase } 3 \uparrow \text {, caspase } 8 \uparrow \text {, caspase } 9 \uparrow \text {, cleaved } \\
\text { caspase8 } 8, \text { bcl- } 2 \downarrow\end{array}$ & (Jiang et al., 2018) \\
\hline & $\begin{array}{l}\text { Eca-109 cells; Eca-109 tumor } \\
\text { bearing male nude BALB/c mice }\end{array}$ & $\begin{array}{l}\text { Apoptosis } \uparrow \text {, proliferation } \downarrow \text {, } \\
\text { cell cycle arrest, tumor } \\
\text { volume } \downarrow\end{array}$ & $\mathrm{P} 53 \uparrow, \mathrm{p} 21 \uparrow, \mathrm{bid} \uparrow, \mathrm{bcl}-2 \downarrow$ & (Wang et al., 2014) \\
\hline Cervical cancer & $\begin{array}{l}\text { Hela, C33A cells; Hela tumor bearing } \\
\text { BALB/c athymic nude mice }\end{array}$ & $\begin{array}{l}\text { Apoptosis } \uparrow \text {, proliferation } \downarrow \text {, } \\
\text { migration } \downarrow \text {, tumor volume } \downarrow\end{array}$ & MMP2 $\downarrow$, MMP9 $\downarrow$, p38 $\downarrow, p-A K T \downarrow, p 65 \downarrow$ & (Wu X. et al., 2017) \\
\hline $\begin{array}{l}\text { urothelial bladder } \\
\text { cancer } \\
\text { (Matrine\&Cisplatin) }\end{array}$ & EJ, T24, BIU, 5637 cells & $\begin{array}{l}\text { Apoptosis } \uparrow \text {, proliferation } \downarrow \text {, } \\
\text { migration } \downarrow \text {, EMT } \downarrow \text {, ROS } \\
\text { generation } \uparrow \text {, cell cycle } \\
\text { arrest }\end{array}$ & $\begin{array}{l}\text { E-cadherin } \uparrow, \beta \text {-catenin } \uparrow \text {, fibronectin } \downarrow \text {, vimentin } \downarrow \text {, } \\
\text { VEGFR } 2 \downarrow, \text { VEGF } \downarrow \text {, cleaved caspase } 3 \uparrow, \text { bcl- } 2 \downarrow\end{array}$ & (Liao et al., 2017) \\
\hline Rhabdomyosarcoma & RD cells & $\begin{array}{l}\text { Apoptosis } \uparrow \text {, proliferation } \downarrow \text {, } \\
\text { migration } \downarrow\end{array}$ & $\mathrm{p}-\mathrm{MEK} 1 \downarrow, \mathrm{p}-\mathrm{ERK} 1 / 2 \downarrow, \mathrm{bcl}-2 \downarrow$, bax $\uparrow$ & (Yan et al., 2017) \\
\hline $\begin{array}{l}\text { Rhabdomyosarcoma } \\
\text { (Matrine\&cisplatin) }\end{array}$ & RD cells & Apoptosis $\uparrow$, proliferation $\downarrow$ & $\mathrm{XIAP} \downarrow$ & (Li L. et al., 2016) \\
\hline $\begin{array}{l}\text { multiple myeloma } \\
\text { (Matrine\&CYC116) }\end{array}$ & RPMI8226 cells & Apoptosis $\uparrow$, proliferation $\downarrow$ & $\begin{array}{l}\text { Cleaved caspase9 } \uparrow \text {, cleaved caspase } 3 \uparrow \text {, cleaved } \\
\text { PARP } \uparrow, \text { bax } \uparrow, \text { mcl- } 1 \downarrow, \text { bcl- } 2 \downarrow, \mathrm{PI} 3 \mathrm{~K} \downarrow, \mathrm{p}-\mathrm{AKT} \downarrow, \mathrm{NF}-\kappa \mathrm{B} \downarrow\end{array}$ & (Zhou et al., 2015) \\
\hline \multirow[t]{2}{*}{ Melanoma } & A375, SK-MEL-2 cells & $\begin{array}{l}\text { Apoptosis } \uparrow \text {, proliferation } \downarrow \text {, } \\
\text { migration } \downarrow\end{array}$ & miR-19b-3p $\downarrow$, PTEN $\uparrow$ & (Wei Y. et al., 2018) \\
\hline & M21 cells & $\begin{array}{l}\text { Apoptosis } \uparrow, \text { proliferation } \downarrow \text {, } \\
\text { cell cycle arrest }\end{array}$ & $\mathrm{p} 21 \uparrow$, cyclinD1 $\downarrow$, bax $\uparrow, \mathrm{bcl}-2 \downarrow, \mathrm{PTEN} \uparrow, \mathrm{p}-\mathrm{PI} 3 \mathrm{~K} \downarrow$ & (Jin et al., 2013) \\
\hline
\end{tabular}

mature oligodendrocytes and promote the formation of axonal myelin sheath in mice with autoimmune encephalomyelitis, which is related to $\mathrm{PI} 3 \mathrm{~K} / \mathrm{AKT} / \mathrm{mTOR}$ signaling pathway (Liu S. Q. et al., 2017). Matrine acts on experimental autoimmune encephalomyelitis (EAE) rats, which can upregulate the level of NGF and its receptor TrkA, inhibit the apoptosis of oligodendrocyte (OLG), and delay the course of disease (Zhu et al., 2016). In addition, this effect is also related to the downregulation of IL-33/ST2 expression in spinal cord of EAE rats (Zhao et al., 2016).

\section{Respiratory Diseases \\ Asthma}

Matrine inhibits NF- $\kappa B$ signaling in airway epithelial cells and asthmatic mice, downregulates the expression of cytokine signaling 3 (SOCS3), and inhibits airway inflammation (Sun et al., 2016). Matrine can significantly reduce airway hyperresponsiveness (AHR) in asthmatic mice, and inhibit goblet cell hyperplasia, eosinophil infiltration and inflammatory response in lung tissue of asthmatic mice. Matrine also reduced the levels of Th2 cytokines and chemokines in bronchoalveolar lavage fluid and inhibited the production of OVA-IgE in serum. In addition, matrine treatment of activated BEAS-2B cells reduces the production of proinflammatory cytokines and eosinophil chemokines, as well as inhibits intercellular cell adhesion molecule (ICAM-1) expression and thus inhibits the adhesion of eosinophils and inflammatory BEAS-2B cells in vitro. Matrine can improve allergic asthma in mice and therefore has potential therapeutic potential (Huang et al., 2014).

\section{Lung Injury}

Matrine protects LPS-induced acute lung injury by inhibiting inflammatory responses, which may involve inhibition of ROS and tissue oxidative stress (Zhang et al., 2011).

\section{Circulatory Diseases \\ Cardiac Fibrosis}

Cardiac fibrosis is one of the pathological features of diabetic cardiomyopathy (DBCM). Matrine can block transforming growth factor $\beta 1 /$ receptor-regulated Smad (TGF $\beta 1 /$ RSMAD) signal transduction, inhibit collagen production and deposition in cardiac tissue, and alleviate high glucose-induced left ventricle. Impaired function and cardiac compliance (Zhang et al., 2018c). High glucose incubation induced activating transcription factor 6 (ATF6) signaling activation in CFS cultured in vitro, thereby increasing ECM synthesis. Matrine can inhibit ATF6, reduce myocardial fibrosis, and improve left ventricular function (Liu et al., 2017b).

\section{Myocardial Ischemia}

Myocardial ischemia is an important pathological process of coronary artery disease and has an important impact on cardiovascular outcomes (Rezende et al., 2019). Control of myocardial ischemia plays a very important role in coronary artery disease. Zhao et al. reported that matrine can alleviate 


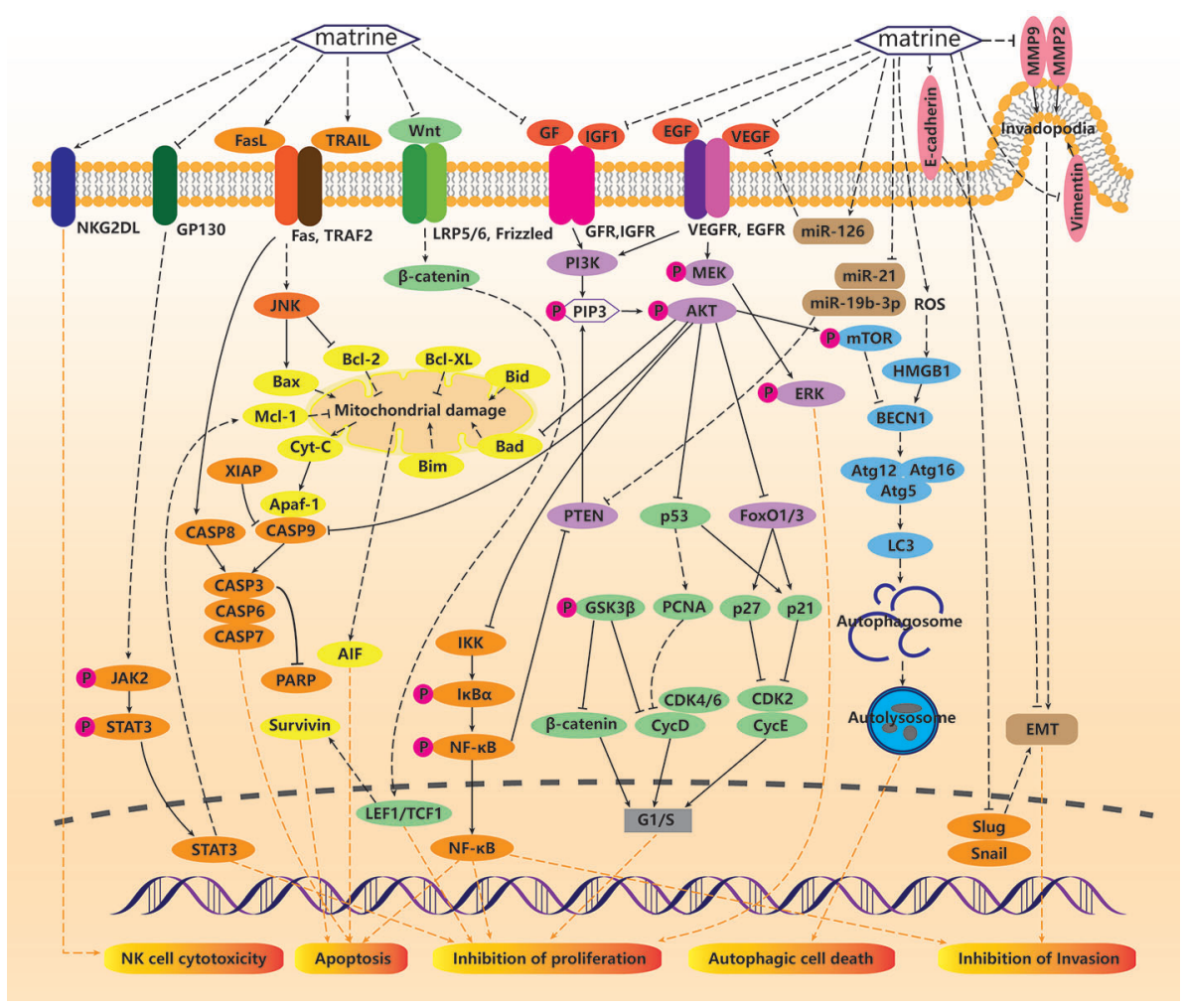

FIGURE 1 | Anticancer mechanisms of matrine. For tumor cells, matrine can induce caspase-mediated exogenous apoptosis by activating Fas/Fas-L and TRAIL. Matrine can also induce mitochondrial damage by promoting the proapoptotic genes Bax, Bid, Bad, Bim, and downregulating the apoptosis-inhibiting genes Bcl-2, $\mathrm{Mcl}-1, \mathrm{Bcl}-\mathrm{XL}$, and release Cyt-C and AIF to promote endogenous Apoptosis. Matrine can inhibit tumor cell proliferation through the GP130/JAK/STAT pathway, and can also induce apoptosis and inhibit proliferation by downregulating the expression of survivin through wnt/B-catenin and LEF1/TCF1. Matrine can inhibit insulin-like growth factor (IGF1) and GF and then affect the expression of phosphatidylinositol 3-kinase (PI3k)/AKT, nuclear factor $\kappa B$ (NF- $\mathrm{kB}$ ) signaling pathway, and p53, thereby promoting tumor cell apoptosis, inhibiting proliferation and invasion. Matrine can also induce autophagy through PI3K/AKT/mTOR signaling pathway, causing autophagy related cell death and inhibiting the expression of EGF and vascular endothelial growth factor (VEGF). Matrine can also upregulate E-cadherin, downregulate MMP2, MMP9, and vimentin to inhibit invadopodia, slug, and snail, so as to inhibit epithelial-mesenchymal transition (EMT) and prevent tumor cell invasion. In addition, matrine can also promote the expression of NKG2DL in tumor cells to promote the recognition and killing of NK cells to tumor cells.

apoptosis of cardiac microvascular endothelial cells (CMECs) induced by ischemia/reperfusion, which is related to JAK2/ STAT3 signaling pathway (Zhao et al., 2018). Guo et al. (2018b) reported that matrine alleviated myocardial ischemia/ reperfusion injury in rats by activating JAK2/STAT3 pathway, upregulating the expression of HSP70 and inhibiting myocardial apoptosis.

\section{Diabetic Cardiomyopathy}

Excessive ROS production in DBCM activates TLR-4/MyD-88 signaling, leading to cardiomyocyte apoptosis, while matrine preconditioning improves cardiac function by inhibiting ROS/ TLR-4 signaling pathway (Liu et al., 2015).

\section{Cardiotoxicity}

Matrine has antioxidant properties and can alleviate isoproterenol-induced acute cardiotoxicity in rats ( $\mathrm{Li}$ et al., 2010).

\section{Heart Failure}

Matrine inhibits cardiomyocyte apoptosis through the $\beta 3-\mathrm{AR}$ pathway and improves cardiac function in rats with heart failure (Yu et al., 2014).

\section{Vascular Injury}

Matrine has the potential to treat vascular injury induced by high-fat diet. Matrine can alleviate abnormal lipid metabolism and inflammation in mice fed with high-fat diet, and significantly reduce oxidized low-density lipoprotein (ox-LDL) induced human umbilical vein endothelial cells (HUVECs). Other lial cells, HUVECs) dysfunction, alleviate the reduction of nitric oxide release, reduce the production of ROS, increase the expression of phosphorylated AKT-Ser473 and endothelial nitric oxide synthase-Ser1177 (eNOS-Ser1177). It can also downregulate the expression of eNOS-Thr495, a negative regulator of eNOS controlled by protein kinase $\mathrm{C} \alpha(\mathrm{PKC} \alpha)$. Computational virtual docking analysis (AutoDock Vina 
software) and biochemical analysis showed that matrine affected eNOS/NO by inhibiting PKC $\alpha$, and the protective effect of matrine could be eliminated by using PKC $\alpha$ and PI3K inhibitors (Zhang et al., 2019). Liu et al. (2018) reported that matrine can reduce AGEs-mediated Notch signal activation in human coronary smooth muscle cells (HCSMC), downregulate the expression levels of nicd1, hes1, collagen I, collegen VIII, and collagen secretion in HCSMC, and block the precondition of atheromatous plaque formation.

A cause of diabetic angiopathy is a high level of advanced glycation end products in the blood. Matrine can alleviate the damage of advanced glycation end products to aortic endothelial cells by inhibiting the activation of nod-like receptor protein 3 (NLRP3) inflammatory body mediated by ROS (Zhang et al., 2018d). Liu et al. reported that advanced glycation end products can induce ROS to induce endothelial cell apoptosis, which can lead to diabetic vascular complications. Matrine restored phosphorylation of MKKK3/6 and p38 MAPK, nuclear translocation of nuclear factor-erythroid 2-related factor 2 (Nrf2), binding activity of antioxidant response elements and expression level, inhibited ROS production and endothelial cell apoptosis in vitro and in vivo (Liu et al., 2017a).

\section{Digestive Diseases}

\section{Liver Fibrosis}

Hepatic fibrosis is a wound healing reaction characterized by the accumulation of extracellular matrix after various liver injuries, which leads to the deformation of normal liver structure and develops into cirrhosis and even hepatocellular carcinoma (Lin et al., 2018). Controlling liver fibrosis in time can prevent the transformation of malignant diseases. Mahzari et al. (2018) reported that in two models of liver fibrosis with abnormal glucose metabolism induced by high fructose diet (HFRU), high fat diet (HF) and low dose streptozotocin (STZ), matrine intervention can upregulate heat-shock protein 72 (HSP72) to inhibit liver fibrosis and improve blood sugar level. For carbon tetrachloride (CCl4)-treated hepatic stellate cell inflammation and fibrosis models, matrine can inhibit the production of MCP1 and reduce the infiltration of Gr1(hi) monocytes in liver tissue, reducing liver inflammation and fibrosis (Shi et al., 2013).

\section{Fatty Liver}

Matrine can inhibit blood sugar and lipid abnormalities in mice fed with high-fat diet and alleviate liver steatosis. Compared with metformin, matrine neither inhibits mitochondrial respiration nor activates AMPK in liver. The regulation of matrine is related to the activation of HSP72 (Zeng et al., 2015).

\section{Pancreatic Fibrosis}

Matrine can alleviate rat pancreatic fibrosis induced by Trinitrobenzene sulfonic acid. Matrine reduces glandular hyperplasia, reduces mitochondrial swelling of acinar cells, and downregulates $\alpha$-smooth muscle actin ( $\alpha$-SMA), TGF- $\beta$, and collagen In addition, Smad2, T $\beta R 1$, and T $\beta R 2$ were significantly downregulated in mRNA and protein levels (Liu et al., 2019).

\section{Colitis}

Matrine can alleviate the symptoms of spontaneous colitis in IL10 deficient mice and reduce the expression levels of IL-12/ $23 \mathrm{p} 40$, interferon- $\gamma(\mathrm{IFN}-\gamma)$, IL-17 in colon tissues $(\mathrm{Wu}$ et al., 2016).

\section{Urinary System Disease Adriamycin-Induced Nephropathy}

Matrine can alleviate nephropathy caused by doxorubicin treatment via the Foxp3/ROR $\gamma$ t pathway [111].

\section{Immune System Disease}

\section{Rheumatoid Arthritis}

Overproliferation and intrinsic resistance to apoptosis of fibroblast-like synoviocytes (FLS) are important pathogenesis of RA. Matrine can reduce arthritis index (AI) by acting on collagen-induced arthritis (CIA) model in rats. In vitro, matrine inhibits the proliferation of FLS, induces cell cycle arrest of G0/ G1 cells, and inhibits the activation of JAK/STAT signaling pathway, thereby increasing the apoptotic rate in vitro (Yang Y. et al., 2017). Rat rheumatoid arthritis model is characterized by Th1/Th2 imbalance. Matrine reduces the level of Th1 cytokines, such as IFN- $\gamma$, tumor necrosis factor (TNF- $\alpha$ ), IL$1 \beta$, by regulating the NF- $\kappa \mathrm{B}$ signaling pathway, and increases Th2 cytokines (IL-4 and IL-10) to balance the Th1/Th2 axis (Niu et al., 2017).

\section{Osteopathy \\ Osteoporosis}

The imbalance between the osteogenic effects of osteoblasts and the osteoclasts of osteoclasts is one of the pathogenesis of postmenopausal osteoporosis. Secretion of estrogen causes an increase in the level of proinflammatory cytokines. Inflammation-induced osteoclast hyperactivity plays a crucial role in the imbalance. Matrine can inhibit osteoclastogenesis, inhibit inflammation and alleviate osteoporosis by regulating the NF-KB/AKT/MAPK pathway (Chen et al., 2017b).

\section{Chondropathy}

Matrine can inhibit the activation of MAPK and NF- $\kappa B$ in human chondrocytes in vitro to inhibit IL-1 $\beta$-induced MMP expression, thereby inhibiting MMP degradation of extracellular matrix and inhibiting chondrocyte apoptosis (Lu et al., 2015).

\section{Mental Disease}

\section{Anxiety and Depression Induced by Liver Injury}

Matrine can alleviate neuro-inflammation and oxidative stress in the brain caused by acute liver injury, thus producing antianxiety and antidepression effects. CCl4 induces acute liver injury in mice. Matrine pretreatment can significantly improve anxiety and depression-like behavior, alleviate neuro-inflammation, downregulate the levels of proinflammatory factors TNF- $\alpha$, IL$1 \beta$, and IL-6, and increase the levels of glutathione (GSH), catalase (CAT), and glutathione S-transferase in brain tissue of mice. The level of GST decreased the levels of MDA and nitrite in 
brain tissue, thus reducing the oxidative stress induced by $\mathrm{CCl} 4$. Matrine significantly reduced the contents of corticosterone, ammonia, glutamic oxalate transaminase, glutamic oxalate transaminase and creatinine, and significantly improved $\mathrm{CCl} 4$ induced liver morphological damage. Matrine treatment increased the levels of glial fibrillary acidic protein (GFAF) positive astrocytes, brain-derived neurotrophic factor (BDNF), and VEGF in the hippocampus of mice to promote neurogenesis and inhibit hippocampal neuronal apoptosis (Khan et al., 2019).

\section{Cancer-Associated Skeletal Muscle Atrophy}

Cancer cachexia is a complex condition secondary to systemic progressive dysfunction and tissue atrophy secondary to cancer. Cancer cachexia is characterized by systemic inflammation, negative energy, and protein balance, generally with weight loss associated with skeletal muscle atrophy, and adipose tissue depletion (Argiles et al., 2010; Fearon et al., 2011). Matrine can increase muscle fiber size and muscle mass in a mouse model of CT26 colon cancer cachexia in vivo. At the same time, it relieves cachexia symptoms such as body and organ weight loss. In vitro, matrine also attenuated dexamethasone, TNF- $\alpha$, and conditioned medium-induced $\mathrm{c} 2 \mathrm{c} 12$ myotube atrophy and apoptosis. This process is associated with activation of the $\mathrm{AKT} / \mathrm{mTOR} /$ Foxo $3 \alpha$ signaling pathway. In addition, matrine downregulates the expression of the E3 ubiquitin ligases musclespecific RING finger protein 1 (MuRF1) and muscle atrophy Fbox protein (MAFbx) (Chen et al., 2019).

Non-antitumor related studies of matrine are summarized in Table 2, and the mechanisms of actions are summarized in Figure 2.

\section{DISCUSSION AND PROSPECT}

Cancer is one of the most serious diseases in the history of human health, for which the whole society bears a huge material and spiritual burden. In 2018, it is estimated that 18.1 million new cancer cases and 9.6 million cancer deaths will occur globally (Bray et al., 2018). With the development of cancer treatment methods, the overall survival rate of cancer has increased, but it is still not optimistic (Allemani et al., 2018). Currently, the main methods of cancer treatment are surgery, chemotherapy, radiotherapy, and targeted therapy. In recent years, immunotherapy represented by immuno-checkpoint inhibitors, chimeric antigen receptor- $\mathrm{T}$ (CAR-T) therapy and cancer vaccine has made tremendous progress (Yang, 2015). But immunotherapy is not applicable to all cancer patients (Beatty and Gladney, 2015). Although individual cancer vaccines have emerged to respond to individual mutations (Sahin and Tureci, 2018), the high cost of treatment makes it impossible to benefit most patients. In short, the treatment of cancer cannot meet the current situation.

Natural product therapy (NPT), as an alternative treatment for cancer, has attracted much attention. Many natural products have high potential for direct treatment of cancer (Newman and
Cragg, 2016; Dutta et al., 2019), or have the effect of improving drug resistance and enhancing the efficacy of anticancer drugs. At present, the dosage forms are also constantly upgrading (Gerber et al., 2013; Watkins et al., 2015; Kashyap et al., 2019). Compared with targeted therapy and immunotherapy, natural products have great advantages in cost, which deserve further research and clinical promotion. Matrine is a natural product with a variety of activities and high conversion value.

Matrine can inhibit the proliferation of more than ten kinds of tumor cells, mostly by inducing apoptosis, blocking cell cycle and inhibiting cell migration. Matrine can also induce autophagy of tumor cells, such as hepatocellular carcinoma cells (Zhang et al., 2010; Xie et al., 2015; Yang and Yao, 2015), gastric cancer cells (Li et al., 2013; Wang et al., 2013), osteosarcoma cells (Ma K. et al., 2016), acute myeloid leukemia cells (Wu J. et al., 2017). In some tumors, such as hepatocellular carcinoma HepG2 cells (Xie et al., 2015), osteosarcoma MG-63 cells (Ma K. et al., 2016), it is protective autophagy. Matrine can be used in pancreatic cancer and gastric cancer. Inhibiting the protective effect of autophagy, blocking the degradation process of substrates and promoting apoptosis (Li et al., 2013; Wang et al., 2013; Cho et al., 2018). Autophagy is a biological process with multifaceted effects, which can promote cell survival and induce death (Jiang et al., 2019; Mirza-Aghazadeh-Attari et al., 2019). However, the nature of autophagy remains unclear in many studies, and needs to be further explored.

In addition, many derivatives of matrine also have antitumor, antifibrosis, and antiosteoporosis effects. Qian et al. reported that WM130, a matrine derivative, could inhibit the proliferation, invasion and migration of HCC cells by inhibiting EGFR/ERK/ MMP-2 and PTEN/AKT signaling pathways and induce apoptosis of hepatocellular carcinoma cells (Qian et al., 2015). Matrine derivative WM-127 can induce cell cycle arrest and apoptosis of hepatocellular carcinoma HepG2, Hep3B, Huh7, LM3, SMMC-7721 by regulating Survivin/beta-catenin signaling pathway (Yin et al., 2018). Matrine derivatives (6aS, 10S, 11aR, 11bR, 11cS)-10-methylamino-dodecahydro-3a, 7a-diazabenzo (de) (MASM) can inhibit the proliferation, cell cycle and apoptosis of hepatocellular carcinoma cells through PI3K/ $\mathrm{AKT} / \mathrm{mTOR}$ and $\mathrm{AKT} / \mathrm{GSK} 3 \beta / \beta$-catenin signaling pathways, inhibit the growth of tumors and inhibit the dryness of tumor cells (Liu Y. et al., 2017). MASM can also inhibit ribosomal protein S5 (RPS5), and regulate PI3K/AKT, NF- $\kappa B$, and MAPKS pathways to inhibit osteoclastogenesis. MASM has the potential to become a drug for osteoporosis (Chen et al., 2017a). Xu et al. reported that WM130, a matrine derivative, could inhibit apoptosis, ECM deposition, TGF- $\beta /$ Smad and Ras/ERK pathways, HSC-T6 cell activation and hepatic fibrosis in rats (Xu et al., 2015).

Matrine can regulate noncoding RNA and then affect key molecules related to cancer progression, such as upregulation of miR-126 to inhibit VEGF (An et al., 2016), downregulation of miR-21 and miR-19b-3p, and alleviate the inhibition of PTEN (Lin et al., 2014; Wei Y. et al., 2018).

Matrine has strong antiinflammatory and antiapoptotic effects in nonneoplastic diseases, such as protecting normal 
TABLE 2 | Non-anticancer studies of matrine.

\begin{tabular}{|c|c|c|c|c|}
\hline Diseases & Models & Effects & Mechanisms & References \\
\hline \multirow[t]{2}{*}{$\begin{array}{l}\text { Alzheimer's } \\
\text { disease }\end{array}$} & $\begin{array}{l}\text { A } 142 \text { treated SH-SY5Y cells; APP/PS1 transgenic } \\
\text { mice }\end{array}$ & Cell viability $\uparrow$, inflamation $\downarrow$ & $\begin{array}{l}\text { BACE1 } \downarrow, N F-\kappa B \downarrow, T N F-\alpha \downarrow, I L- \\
1 \beta \downarrow\end{array}$ & (Cui et al., 2017) \\
\hline & A $\beta 1-42$ treated Sprague Dawley rats & $\begin{array}{l}\text { Cognitive ability (water maze test) } \uparrow \text {, } \\
\text { novel object recognition test } \uparrow\end{array}$ & 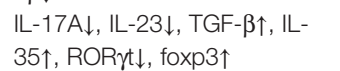 & $\begin{array}{l}\text { (Zhang L. et al., } \\
\text { 2015) }\end{array}$ \\
\hline Cerebral ischemia & MCAO mice & Brain infract volume $\downarrow$, apoptosis $\downarrow$, & $\begin{array}{l}\text { Caspase } 3 \downarrow \text {, bax } \downarrow \text {, bcl- } 2 \uparrow, \\
\text { MDA } \downarrow, \text { SOD } \uparrow, \mathrm{GSH}-\mathrm{Px} \uparrow \\
\text { CAT } \uparrow\end{array}$ & (Zhao et al., 2015) \\
\hline Spinal cord injury & Cortical neurons; female ddY mice & $\begin{array}{l}\text { Motor dysfunction } \downarrow \text {, density of } 5-\mathrm{HT} \text { - } \\
\text { positive tracts } \uparrow\end{array}$ & HSP90 & $\begin{array}{l}\text { (Tanabe et al., } \\
\text { 2018) }\end{array}$ \\
\hline $\begin{array}{l}\text { Autoimmune } \\
\text { encephalomyelitis }\end{array}$ & EAE C57BL/6 mice model & $\begin{array}{l}\text { OPC proliferation } \uparrow \text {, oligodendrocyte } \\
\text { numbers and PLP expression } \uparrow\end{array}$ & $\begin{array}{l}\mathrm{p}-\mathrm{PI} 3 \mathrm{~K} \uparrow, \mathrm{p}-\mathrm{AKT} \uparrow, \mathrm{p}-\mathrm{mTOR} \uparrow \\
\mathrm{p}-\mathrm{p} 70 \mathrm{~S} 6 \mathrm{~K} \uparrow\end{array}$ & $\begin{array}{l}\text { (Liu S. Q. et al., } \\
\text { 2017) }\end{array}$ \\
\hline \multirow[t]{2}{*}{ Multiple sclerosis } & $\begin{array}{l}\text { experimental autoimmune encephalomyelitis female } \\
\text { WISTAR rats }\end{array}$ & OLG apoptosis $\downarrow$ & $\mathrm{NGF} \uparrow, \operatorname{trkA} \uparrow$ & (Zhu et al., 2016) \\
\hline & $\begin{array}{l}\text { experimental autoimmune encephalomyelitis female } \\
\text { WISTAR rats }\end{array}$ & Clinical score $\downarrow$ & 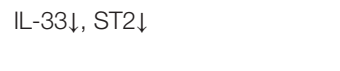 & (Zhao et al., 2016) \\
\hline \multirow[t]{2}{*}{ Asthma } & $\begin{array}{l}\text { human bronchial epithelial cell line BEAS-2B and } \\
\text { MLE-12 mouse lung epithelial cells; OVA treated } \\
\text { female BALB/c mice }\end{array}$ & Asthmatic symptoms $\downarrow$, inflamation $\downarrow$ & $\begin{array}{l}\text { SOCS3 } \downarrow, \text { ICAM1 } \downarrow, \text { VCAM } 1 \downarrow \text {, } \\
\text { p-p65 } \downarrow\end{array}$ & (Sun et al., 2016) \\
\hline & $\begin{array}{l}\text { BEAS-2B cells; Ovalbumin(OVA) treated female } \\
\text { BALB/c mice }\end{array}$ & $\begin{array}{l}\text { Inflamation } \downarrow \text {, airway } \\
\text { hyperresponsiveness } \downarrow\end{array}$ & $\begin{array}{l}\| L-4 \downarrow,|\mathrm{L}-5 \downarrow,| \mathrm{L}-6 \downarrow, \mid \mathrm{L}-13 \downarrow \\
\mathrm{TNF}-\alpha \downarrow, \lg \mathrm{\downarrow}\end{array}$ & (Huang et al., 2014) \\
\hline Lung injury & LPS treated male BALB/c mice & Inflamation $\downarrow$, survival $\uparrow$ & $\begin{array}{l}\text { MPO } \downarrow \text {, MDA } \downarrow \text {, plasma TNF- } \\
\alpha \downarrow, I L-6 \downarrow, \text { HMGB } 1 \downarrow \text {, p-NF- } \\
\kappa B \downarrow\end{array}$ & (Zhang et al., 2011) \\
\hline \multirow[t]{2}{*}{$\begin{array}{l}\text { Diabetic } \\
\text { cardiomyopathy }\end{array}$} & $\begin{array}{l}\text { HG medium cultured cardiac fibroblasts; } \\
\text { streptozotocin treated Sprague Dawley rats }\end{array}$ & $\begin{array}{l}\text { Fibrosis } \downarrow \text {, left ventricular functions } \uparrow \text {, } \\
\text { cardiac compliance loss } \downarrow\end{array}$ & $\begin{array}{l}\text { TGF- } \beta 1 \downarrow, \text { p-smad } 2 \downarrow, \text { p- } \\
\text { smad3 } \downarrow \text {, smad7 } 7 \downarrow \text {, collagen } \mid \downarrow\end{array}$ & $\begin{array}{l}\text { (Zhang et al., } \\
\text { 2018c) }\end{array}$ \\
\hline & Streptozotocin treated male Sprague Dawley rats & Myocyte apoptosis $\downarrow$, ROS generation $\downarrow$ & $\begin{array}{l}\text { MDA } \downarrow, \text { GPx } \uparrow, T L R 4 \downarrow, \text { MyD- } \\
88 \downarrow \text {, cleaved-caspase } 8 \downarrow \text {, } \\
\text { cleaved-caspase } \downarrow \downarrow\end{array}$ & (Liu et al., 2015) \\
\hline Cardiac fibrosis & $\begin{array}{l}\text { cardiac fibroblasts from 2-day-old Sprague Dawley } \\
\text { rats; streptozotocin treated Sprague Dawley rats }\end{array}$ & $\begin{array}{l}\text { Cardiac systolic/diastolic dysfunction } \downarrow \text {, } \\
\text { cardiac compliance } \uparrow\end{array}$ & $\begin{array}{l}\text { ATF6 } \downarrow \text {, miR455 } \uparrow \text {, calreticulin } \downarrow \text {, } \\
\text { fibronectin } \downarrow \text {, collagen } \mid \downarrow\end{array}$ & (Liu et al., 2017b) \\
\hline $\begin{array}{l}\text { Hypoxia/ } \\
\text { reoxygenation } \\
\text { induced cardiac } \\
\text { microvascular } \\
\text { endothelial cells } \\
\text { death }\end{array}$ & $\begin{array}{l}\text { oxygen free anoxic solution treated rat cardiac } \\
\text { microvascular endothelial cells (CMECs) }\end{array}$ & Apoptosis $\downarrow$, tube formation ability $\uparrow$ & $\begin{array}{l}\mathrm{p}-\mathrm{JAK} 2 \uparrow, \mathrm{p}-\mathrm{STAT} 3 \uparrow, \mathrm{bcl}-2 \uparrow \\
\mathrm{bax} \downarrow\end{array}$ & (Zhao et al., 2018) \\
\hline $\begin{array}{l}\text { Myocardial } \\
\text { ischemia/ } \\
\text { reperfusion (I/R) } \\
\text { injury }\end{array}$ & $\begin{array}{l}\text { neonatal rat cardiomyocytes; Male Sprague Dawley } \\
\text { rats }\end{array}$ & Cell viability $\uparrow$ & 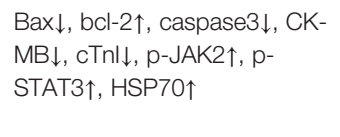 & (Guo et al., 2018b) \\
\hline $\begin{array}{l}\text { Isoproterenol- } \\
\text { induced acute } \\
\text { cardiotoxicity }\end{array}$ & Isoproterenol treated male Sprague Dawley rats & Heart function $\uparrow$, inflamation $\downarrow$ & $\begin{array}{l}\text { SOD, catala, glutathione } \\
\text { peroxidase } \uparrow, \text { MDA } \downarrow\end{array}$ & (Li et al., 2010) \\
\hline Heart failure & $\begin{array}{l}\text { Apply coronary artery ligation to establish rat heart } \\
\text { failure model }\end{array}$ & Cardiac function $\uparrow$, apoptosis $\downarrow$ & $\begin{array}{l}\text { Cleaved caspase } 3 \downarrow \text {, bax } \downarrow \text {, } \\
\text { bcl- } 2 \uparrow, \beta 3 A R \downarrow \text {, eNOS } \downarrow\end{array}$ & (Yu et al., 2014) \\
\hline $\begin{array}{l}\text { Lipid metabolism } \\
\text { disorders caused } \\
\text { vascular } \\
\text { endothelial injury }\end{array}$ & $\begin{array}{l}\text { The HUVECs treated with ox-LDL; Male C57BL/6 } \\
\text { mice were given high-fat diet for } 12 \text { weeks }\end{array}$ & $\begin{array}{l}\text { Lipid metabolism } \uparrow \text {, inflamation } \downarrow \text {, } \\
\text { thickness of vascular wall } \downarrow \text {, ox-LDL- } \\
\text { induced apoptosis } \downarrow\end{array}$ & 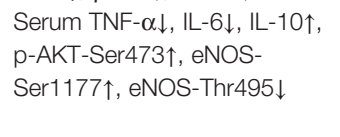 & (Zhang et al., 2019) \\
\hline Atherosclerosis & AGEs treated HCSMCs & $\begin{array}{l}\text { Contractile synthetic phenotypic } \\
\text { conversion } \downarrow\end{array}$ & $\begin{array}{l}\text { DLL4 } 4 \downarrow \text {, notch } \uparrow \text {, collagen } \mid \downarrow \text {, } \\
\text { collegen } \text { VIII } \downarrow \text {, NICD } 1 \downarrow \text {, } \\
\text { HES } 1 \downarrow \text {, }\end{array}$ & (Liu et al., 2018) \\
\hline $\begin{array}{l}\text { Advanced } \\
\text { glycation end } \\
\text { products (AGEs) } \\
\text { induced damage } \\
\text { in the arterial } \\
\text { endothelium; }\end{array}$ & AGEs treated human aortic endothelial cells & $\begin{array}{l}\text { Cell viability } \uparrow \text {, infamation } \downarrow \text {, intracellular } \\
\text { reactive oxygen species } \downarrow\end{array}$ & $\begin{array}{l}\text { NLRP3 } \downarrow \text {, ASC } \downarrow \text {, cleaved } \\
\text { caspase- } 1 \downarrow, \mid \mathrm{L}-1 \beta \downarrow\end{array}$ & $\begin{array}{l}\text { (Zhang et al., } \\
\text { 2018d) }\end{array}$ \\
\hline $\begin{array}{l}\text { Diabetic vascular } \\
\text { complications }\end{array}$ & $\begin{array}{l}\text { AGEs treated Sprague Dawley rats; Rat aortic } \\
\text { endothelial cells }\end{array}$ & ROS generation $\downarrow$, apoptosis $\downarrow$ & $\begin{array}{l}\mathrm{p}-\mathrm{MKK} 3 \uparrow, \mathrm{p}-\mathrm{MKK} 6 \uparrow, \mathrm{p}-38 \uparrow \\
\mathrm{HO} 1 \uparrow, \mathrm{NQO} 1 \uparrow, \mathrm{nrf} 2 \uparrow\end{array}$ & (Liu et al., 2017a) \\
\hline $\begin{array}{l}\text { Hepatosteatosis } \\
\text { with glucose } \\
\text { intolerance }\end{array}$ & $\begin{array}{l}\text { high-fructose diet (HFru) induced hepatosteatosis } \\
\text { and glucose intolerance from hepatic, and } \\
\text { hepatosteatosis and hyperglycemia induced by }\end{array}$ & $\begin{array}{l}\text { Body weight } \downarrow \text {, epididymal fat weight } \downarrow \text {, } \\
\text { triglyceride } \downarrow\end{array}$ & $\begin{array}{l}\text { SREBP-1c } \downarrow, \text { ChREBP } \downarrow, \text { SCD- } \\
1 \downarrow, \text { fas } \downarrow, \text { elF } 2 \alpha \downarrow, \text { CHOP } \downarrow \text {, } \\
\text { IRE } 1 \downarrow, \text { HSP72 } \uparrow\end{array}$ & $\begin{array}{l}\text { (Mahzari et al., } \\
\text { 2018) }\end{array}$ \\
\hline
\end{tabular}


TABLE 2 | Continued

\begin{tabular}{|c|c|c|c|c|}
\hline Diseases & Models & Effects & Mechanisms & References \\
\hline & $\begin{array}{l}\text { high-fat (HF) diet in combination with low doses of } \\
\text { streptozotocin (STZ); C57BL/6J mice }\end{array}$ & & & \\
\hline Liver fibrosis & CCl4 treated C57BL/6mice & Inflamation $\downarrow$ & $\begin{array}{l}\text { MCP- } 1 \downarrow \text {, number of CD } 45^{+} \\
\text {cells } \downarrow \text {, number of Gr1 } 1^{+} \text {cells } \downarrow\end{array}$ & (Shi et al., 2013) \\
\hline Hepatic steatosis & high-fat-fed C57BL/J6 mice & $\begin{array}{l}\text { Glucose intolerance } \downarrow \text {, } \\
\text { hepatosteatosis } \downarrow \text {, inflamation } \downarrow\end{array}$ & 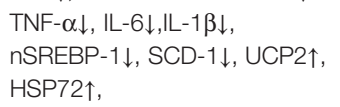 & (Zeng et al., 2015) \\
\hline Pancreatic fibrosis & $\begin{array}{l}\text { Sprague Dawley rats, } 12.5 \mathrm{~mL} \text { of } 2 \% \\
\text { trinitrobenzene sulfonic acid-ethanol phosphate } \\
\text { buffer solution containing } 1 \mathrm{~mL} \text { of } 5 \% \\
\text { trinitrobenzene sulfonic acid and } 1.5 \mathrm{~mL} \text { of } 10 \% \\
\text { ethanol phosphate buffer solution were injected in } \\
\text { pumpbiliopancreatic duct with a micro-injection }\end{array}$ & $\begin{array}{l}\text { Mitochondrial swelling of acinous } \\
\text { cells } \downarrow \text {, hyperplasia of glandules } \downarrow \text {, } \\
\text { fibrosis } \downarrow\end{array}$ & $\begin{array}{l}\alpha-S M A \downarrow, \text { TGF- } \beta 1 \downarrow \text {, collagen } \\
\downarrow \downarrow, \text { smad } 2 \downarrow, T \beta R 1 \downarrow, \text { T } \beta R 2 \downarrow\end{array}$ & (Liu et al., 2019) \\
\hline Chronic colitis & IL-10 deficient mice & Inflamation $\downarrow$ & $|\mathrm{IFN}-\gamma \downarrow,| \mathrm{L}-17 \downarrow$ & (Wu et al., 2016) \\
\hline $\begin{array}{l}\text { Adriamycin- } \\
\text { induced } \\
\text { nephropathy }\end{array}$ & Adriamycin treated male Sprague Dawley rats & Renal function $\uparrow$, inflamation $\downarrow$ & Foxp3 $\uparrow, \mathrm{ROR} \gamma \mathrm{t} \downarrow$ & (Xu et al., 2016) \\
\hline \multirow[t]{2}{*}{$\begin{array}{l}\text { Rheumatoid } \\
\text { arthritis }\end{array}$} & $\begin{array}{l}\text { Bovine type II collagen treated fibroblast-like } \\
\text { synoviocytes; bovine type II collagen treated male } \\
\text { Sprague Dawley rats }\end{array}$ & $\begin{array}{l}\text { Apoptosis } \uparrow \text {, proliferation } \downarrow \text {, cell cycle } \\
\text { arrest, arthritis index } \downarrow\end{array}$ & $\begin{array}{l}\text { p-JAK } 2 \downarrow, \text { p-STAT } 1 \downarrow, \text { p- } \\
\text { STAT3 } \downarrow \text {, bax } \uparrow, \text { bcl- } 2 \downarrow \text {, } \\
\text { caspase } 3 \uparrow\end{array}$ & $\begin{array}{l}\text { (Yang Y. et al., } \\
\text { 2017) }\end{array}$ \\
\hline & $\begin{array}{l}\text { bovine type II collagen treated male Sprague } \\
\text { Dawley rats; phorbol myristate acetage (PMA) and } \\
\text { ionomycin treated BALB/c mice splenic } \mathrm{CD}^{+} \mathrm{T} \\
\text { lymphocytes }\end{array}$ & Inflamation $\downarrow$ & $\begin{array}{l}\mathrm{p} 65 \downarrow, \mathrm{p}-\mathrm{|} \kappa \mathrm{B} \alpha \downarrow, \mathrm{IFN}-\gamma \downarrow, \mathrm{TNF}- \\
\alpha \downarrow,|\mathrm{L}-1 \beta \downarrow,| \mathrm{L}-4 \uparrow, \mathrm{IL}-10 \uparrow\end{array}$ & (Niu et al., 2017) \\
\hline \multirow[t]{2}{*}{ Osteoporosis } & $\begin{array}{l}\text { bone marrow monocytes, RAW264.7 cells; RANKL } \\
\text { treated C57BL/ } 6 \text { mice }\end{array}$ & Osteoclastogenesis $\downarrow$, inflamation $\downarrow$ & 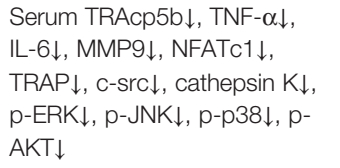 & (Chen et al., 2017b) \\
\hline & $\| \mathrm{L}-1 \beta$ treated human articular cartilage & Apoptosis $\downarrow$, chondrocyte viability $\uparrow$ & $\begin{array}{l}p-p 38 \downarrow, p-E R K \downarrow, p-J N K \downarrow \\
\mid \kappa B \alpha \uparrow\end{array}$ & (Lu et al., 2015) \\
\hline $\begin{array}{l}\text { Acute liver injury } \\
\text { induced } \\
\text { neuroinflammation } \\
\text { and oxidative } \\
\text { stress }\end{array}$ & $\mathrm{CCl} 4$ treated male BALB/c mice & $\begin{array}{l}\text { Food intake } \uparrow \text {, water intake } \uparrow \text {, } \\
\text { inflamation } \downarrow \text {, open field test (OFT) } \uparrow \text {, } \\
\text { elevated plus maze test (EPM) } \uparrow \text {, light- } \\
\text { dark box test (LDB) } \uparrow \text {, forced } \\
\text { swimming test (FST) } \uparrow \text {, and tail } \\
\text { suspension test (TST) } \uparrow \text {, apoptosis } \downarrow\end{array}$ & 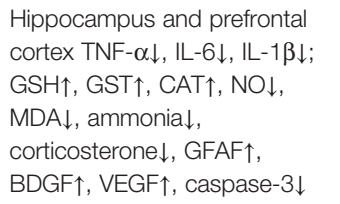 & (Khan et al., 2019) \\
\hline $\begin{array}{l}\text { Cancer induced } \\
\text { cachexia and } \\
\text { muscle atrophy }\end{array}$ & $\begin{array}{l}\text { CT26 tumor bearing BALB/c mice; TNF-alpha, } \\
\text { dexamethasone, conditioned medium treated } \\
\text { C2C12 myotubes }\end{array}$ & $\begin{array}{l}\text { Muscle weight } \uparrow, \text { C2C12 myoblast } \\
\text { differentiation } \uparrow\end{array}$ & $\begin{array}{l}\text { MuRF1 } \downarrow, M A F b x \downarrow, p-A K T \uparrow, p- \\
\text { mTOR } \uparrow, p-F O X O 3 \alpha \uparrow\end{array}$ & (Chen et al., 2019) \\
\hline
\end{tabular}

cells in cell and animal models of AD (Cui et al., 2017), asthma (Sun et al., 2016), lung injury (Zhang et al., 2011), liver fibrosis (Shi et al., 2013), colitis (Wu et al., 2016). Matrine can also upregulate the expression of miR-455, thereby inhibiting fibrin synthesis and alleviating myocardial fibrosis (Liu et al., 2017b).

It is worth noting that matrine can inhibit proliferation and induce apoptosis in cancer cells, while for normal cells in pathological environment, matrine can inhibit apoptosis and maintain growth and proliferation (The signaling pathways and diseases related to the actions of matrine are summarized in Figure 3). NF- $\kappa B$ is involved in the inflammatory response and immune response of the body, and can regulate cell apoptosis and stress response (Pires et al., 2018). Matrine can inhibit NF$\kappa \mathrm{B}$ to inhibit the proliferation, invasion and apoptosis of tumor cells. When normal cells such as nerve cells, tracheal epithelial cells and chondrocytes are under stress, matrine can inhibit NF$\kappa \mathrm{B}$ to inhibit apoptosis and inflammation to maintain the survival of normal cells (Zhang et al., 2011; Lu et al., 2015; Cui et al., 2017; Niu et al., 2017). JAK/STAT regulate the expression of a variety of proteins involved in induction or prevention of apoptosis, and has also become a paradigm for membrane-tonucleus signaling and explains how a broad range of soluble factors, including cytokines and hormones, mediate their diverse functions (Villarino et al., 2015; Bousoik and Montazeri Aliabadi, 2018). Matrine inhibits JAK/STAT pathway to inhibit tumor cell proliferation and inflammation in normal cells (Ma L. et al., 2015; Yang et al., 2015; Guo et al., 2018b; Zhao et al., 2018). The MAPKs in mammals include JNK, p38 MAPK, and ERK. These enzymes are serine-threonine protein kinases that regulate various cellular activities including proliferation, differentiation, apoptosis or survival, inflammation, and innate immunity. The compromised MAPK signaling pathways contribute to the pathology of diverse human diseases (Kim and Choi, 2015; Sun et al., 2015). Matrine negatively regulates the MAPK/ERK pathway, thereby inhibiting tumor cell proliferation and suppressing the inflammatory response or fibrosis in normal 


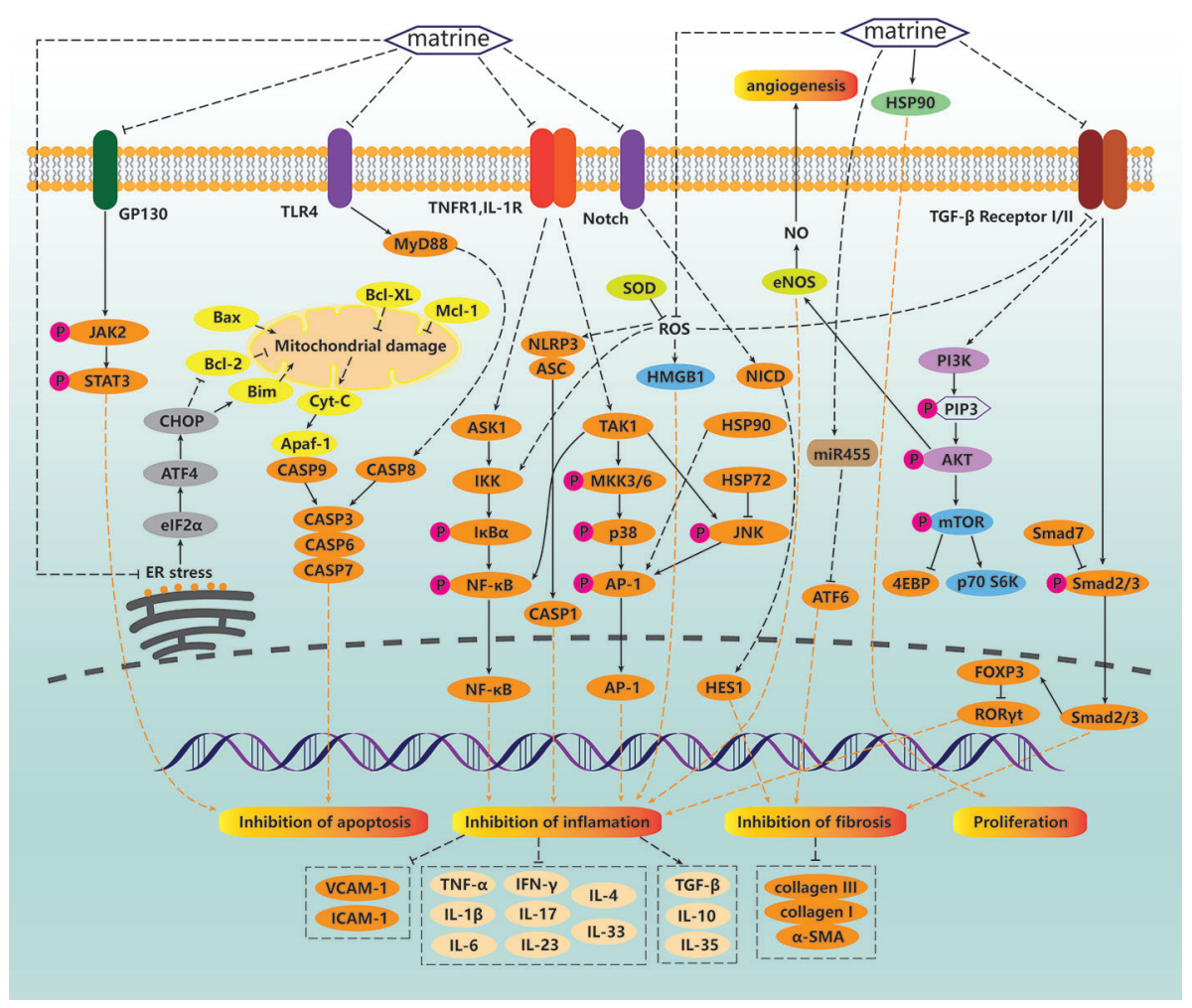

FIGURE 2 | Non-anticancer mechanisms of matrine. For normal cells, matrine can promote cell survival under various stress environments. Under oxidative stress conditions, matrine can inhibit reactive oxygen species (ROS) production, thus inhibiting high mobility group protein box 1 (HMGB1), nod-like receptor protein 3 (NLRP3)/ASC/CASP1 pathway and nuclear factor $\kappa \mathrm{B}$ (NF- $\kappa \mathrm{B}$ pathway)-mediated inflammation. Matrine can also inhibit tumor necrosis factor (TNF)- $\alpha$ and IL-1 induced NF-KB and TAK/JNK/AP1 pathway-mediated inflammation. In addition, TGF $\beta / S m a d / F O X P 3 / R O R \gamma t$ is also a pathway for matrine to inhibit inflammation. Matrine can also block CASP8 mediated exogenous apoptosis by inhibiting TLR4/MyD88 pathway, elF2 $\alpha / A T F 4 / C H O P$ mediated mitochondrial damage, Cyt-C release and CASP9 mediated endogenous apoptosis by inhibiting ER stress. Matrine can also inhibit GP130/JAK/STAT pathway mediated apoptosis. TGF $3 /$ Smad, $\mathrm{NOTCH} / \mathrm{NICD}$, and miR455/ATF6 mediated fibrosis can also be inhibited by matrine. In addition, matrine can promote cell proliferation by activating Hsp90.

cells (Lu et al., 2015; Wang et al., 2015b; Peng et al., 2016; Yan et al., 2017). PI3Ks are crucial coordinators of intracellular signaling in response to the extracellular stimulators. The serine/threonine kinase $\mathrm{AKT}$ is a master regulator of many diverse cellular functions, including survival, growth, metabolism, migration, and differentiation. The signaling axis formed by $\mathrm{PI} 3 \mathrm{~K}$ and $\mathrm{AKT}$, as well as the vast range of downstream substrates is thus central to control of cell physiology in many different contexts and tissues (Noorolyai et al., 2019; Sugiyama et al., 2019). Matrine inhibits the PI3K/ AKT pathway in tumor cells, while the reverse occurs in normal cells (Niu et al., 2014; Xie et al., 2015; Liu S. Q. et al., 2017; Wu X. et al., 2017; Chen et al., 2019; Zhang et al., 2019). Moreover, for tumor cells, matrine induces oxidative stress leading to endogenous apoptosis in cells, while in ischemic disease models, matrine inhibits oxidative stress and thereby inhibits apoptosis of nerve cells and cardiac muscle cells. In different application environments, matrine has contradictory effects. In addition, natural compounds such as resveratrol (Ko et al., 2017; Xia et al., 2017), baicalein (Liu et al., 2016; Sowndhararajan et al., 2017), and quercetin (Li Y. et al., 2016; Massi et al., 2017) also have similar killing and protecting effects. However, there is still no reasonable and accepted explanation for this dualistic effect. We speculate that this phenomenon may be related to different cell properties. We can find tumor cells that cannot be inhibited by matrine and normal cells that cannot be protected in a stressful environment or even directly inhibited, and make a histological analysis of these cells, which may be helpful to find the mechanism of this phenomenon.

The underlying mechanism of matrine's selective killing of cells remains to be explored. The role of matrine in autophagy induction or inhibition needs to be further determined. In addition, the regulation of noncoding RNA by matrine may be an important way for matrine to play its role. Whether there are transcriptome-related intrinsic regulatory roles in all disease models needs to be further explored.

Last but not least, the pharmacokinetics of matrine in different modes of administration need to be further improved. The most common way to take matrine is oral administration. A liquid chromatography/tandem mass spectrometry (LC/MS/MS) developed method facilitated a clinical pharmacokinetic study after oral administration of a single dose of matrine soft gelatin 


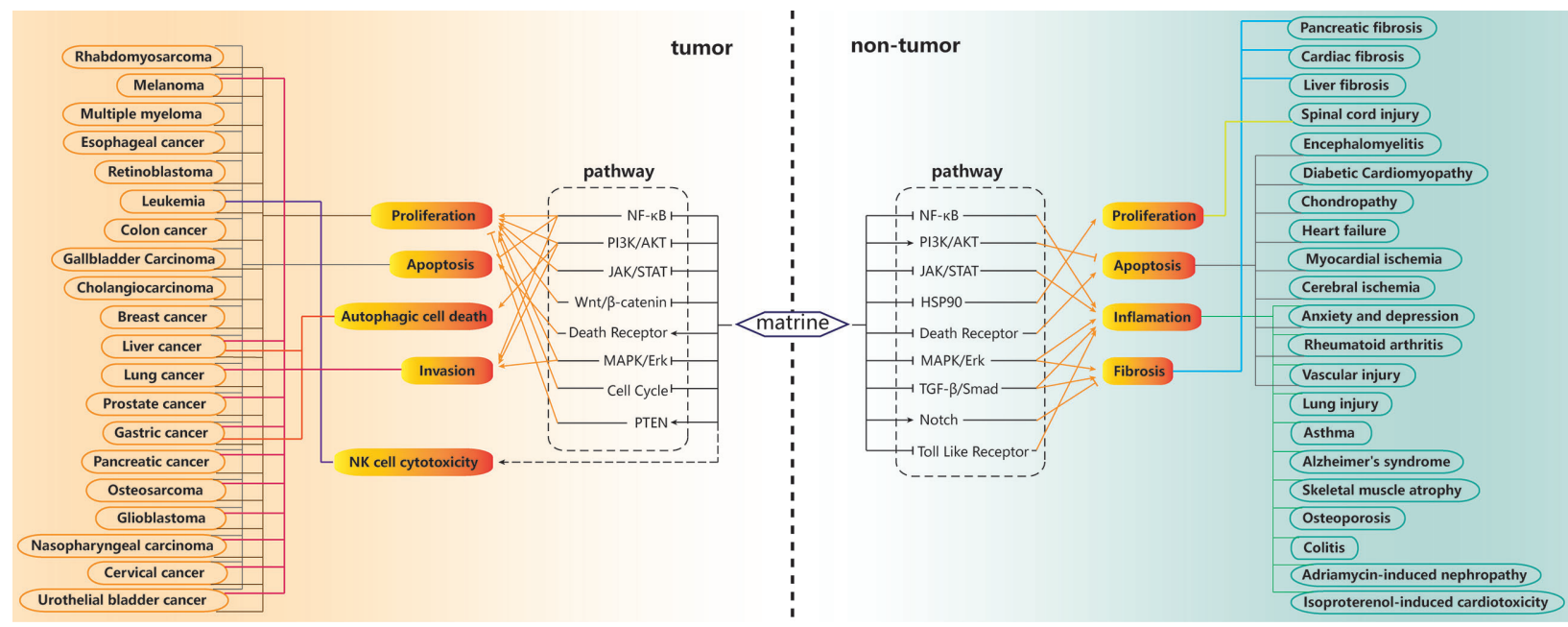

FIGURE 3 | Summary of signal pathways and diseases related to the actions of matrine. For tumor cells, matrine can inhibit proliferation and invasion, promote apoptosis and autophagic cell death, and enhance the cytotoxicity of NK cells. These effects are related to the inhibition of nuclear factor $\kappa \mathrm{B}$ (NF-kB), phosphatidylinositol 3-kinase (PI3K)/AKT, Wnt/B-catenin, mitogen-activated protein kinase (MAPK)/extracellular signal-regulated kinase (ERK) and cell cycle pathways, and promotion of PTEN, death receptor pathways. For normal cells, matrine can promote proliferation, inhibit apoptosis, inflammation and fibrosis. These effects are related to matrine inhibiting NF-KB, JAK/STAT, Hsp90, MAPK/ERK, TGF $\beta /$ Smad, death receptor, toll like receptor pathways, promoting PI3K/AKT, NOTCH pathways.

capsules $(100,200$ and $400 \mathrm{mg})$ in a three-period crossover design. Dose-related linear trends were observed for the $\mathrm{AUC}_{0-}$ ${ }_{t}$ and the $\mathrm{C}_{\max }$ of matrine. The $\mathrm{t}_{1 / 2}$ and the $\mathrm{T}_{\max }$ of matrine were independent of the administered doses (Zhang et al., 2009). Another study explored the pharmacokinetics of matrine through intravenous injection or transdermal administration in rat liver, blood, skin and other organs and tissues, and found that transdermal administration is also a promising way (Tang et al., 2017). At present, there is no pharmacokinetic study of matrine for specific diseases.

In summary, matrine has a wide range of pharmacological effects and high development value, and further mechanism research needs to be carried out.

\section{REFERENCES}

Aghvami, M., Ebrahimi, F., Zarei, M. H., Salimi, A., Pourahmad, J. R., and Pourahmad, J. (2018). Matrine Induction of ROS Mediated Apoptosis in Human ALL B-lymphocytes Via Mitochondrial Targeting. Asian Pac. J. Cancer Prev. 19 (2), 555-560. doi: 10.22034/APJCP.2018.19.2.555

Allemani, C., Matsuda, T., Di Carlo, V., Harewood, R., Matz, M., Niksic, M., et al. (2018). Global surveillance of trends in cancer survival 2000-14 (CONCORD3): analysis of individual records for 37513025 patients diagnosed with one of 18 cancers from 322 population-based registries in 71 countries. Lancet 391, 1023-1075. doi: 10.1016/S0140-6736(17)33326-3

An, Q., Han, C., Zhou, Y., Li, F., Li, D., Zhang, X., et al. (2016). Matrine induces cell cycle arrest and apoptosis with recovery of the expression of miR-126 in the A549 non-small cell lung cancer cell line. Mol. Med. Rep. 14, 4042-4048. doi: 10.3892/mmr.2016.5753

Ao, M., Xiao, X., and Li, Q. (2019). Efficacy and safety of compound Kushen injection combined with chemotherapy on postoperative Patients with breast

\section{AUTHOR CONTRIBUTIONS}

HZ and LC prepared the manuscript. HZ, XS, and QY edited the tables and figures. LW and CG revised the manuscript. All authors approved the final manuscript.

\section{FUNDING}

This work was supported by the National Natural Science Foundation of China (Nos. 81873042, 81872494, and 81803633).

cancer: A meta-analysis of randomized controlled trials. Med. (Baltimore) 98, e14024. doi: 10.1097/MD.0000000000014024

Argiles, J. M., Anker, S. D., Evans, W. J., Morley, J. E., Fearon, K. C., Strasser, F., et al. (2010). Consensus on cachexia definitions. J. Am. Med. Dir. Assoc. 11, 229-230. doi: 10.1016/j.jamda.2010.02.004

Bai, S., Chen, T., Yu, X., Luo, M., Chen, X., Lin, C., et al. (2017). The specific killing effect of matrine on castration-resistant prostate cancer cells by targeting the AKT/FoxO3a signaling pathway. Oncol. Rep. 37, 2819-2828. doi: 10.3892/ or.2017.5510

Ballard, C., Gauthier, S., Corbett, A., Brayne, C., Aarsland, D., and Jones, E. (2011). Alzheimer's disease. Lancet 377, 1019-1031. doi: 10.1016/S0140-6736(10)61349-9

Beatty, G. L., and Gladney, W. L. (2015). Immune escape mechanisms as a guide for cancer immunotherapy. Clin. Cancer Res. 21, 687-692. doi: 10.1158/10780432.CCR-14-1860

Blandin Knight, S., Crosbie, P. A., Balata, H., Chudziak, J., Hussell, T., and Dive, C. (2017). Progress and prospects of early detection in lung cancer. Open Biol. 7 (9), 170070. doi: 10.1098/rsob.170070 
Bousoik, E., and Montazeri Aliabadi, H. (2018). "Do We Know Jack" About JAK? A Closer Look at JAK/STAT Signaling Pathway. Front. Oncol. 8, 287. doi: $10.3389 /$ fonc.2018.00287

Bray, F., Ferlay, J., Soerjomataram, I., Siegel, R. L., Torre, L. A., and Jemal, A. (2018). Global cancer statistics 2018: GLOBOCAN estimates of incidence and mortality worldwide for 36 cancers in 185 countries. CA Cancer J. Clin. 68, 394-424. doi: 10.3322/caac.21492

Cao, J., Wei, R., and Yao, S. (2019). Matrine has pro-apoptotic effects on liver cancer by triggering mitochondrial fission and activating Mst1-JNK signalling pathways. J. Physiol. Sci. 69, 185-198. doi: 10.1007/s12576-018-0634-4

Chang, C., Liu, S. P., Fang, C. H., He, R. S., Wang, Z., Zhu, Y. Q., et al. (2013). Effects of matrine on the proliferation of HT29 human colon cancer cells and its antitumor mechanism. Oncol. Lett. 6, 699-704. doi: 10.3892/ol.2013.1449

Chang, J., Hu, S., Wang, W., Li, Y., Zhi, W., Lu, S., et al. (2018). Matrine inhibits prostate cancer via activation of the unfolded protein response/endoplasmic reticulum stress signaling and reversal of epithelial to mesenchymal transition. Mol. Med. Rep. 18, 945-957. doi: 10.3892/mmr.2018.9061

Chen, S. F., Zhang, Z. Y., and Zhang, J. L. (2017). Matrine increases the inhibitory effects of afatinib on H1975 cells via the IL6/JAK1/STAT3 signaling pathway. Mol. Med. Rep. 16, 2733-2739. doi: 10.3892/mmr.2017.6865

Chen, X., Zhi, X., Cao, L., Weng, W., Pan, P., Hu, H., et al. (2017a). Matrine derivate MASM uncovers a novel function for ribosomal protein S5 in osteoclastogenesis and postmenopausal osteoporosis. Cell Death Dis. 8, e3037. doi: 10.1038/cddis.2017.394

Chen, X., Zhi, X., Pan, P., Cui, J., Cao, L., Weng, W., et al. (2017b). Matrine prevents bone loss in ovariectomized mice by inhibiting RANKL-induced osteoclastogenesis. FASEB J. 31, 4855-4865. doi: 10.1096/fj.201700316R

Chen, L., Chen, L., Wan, L., Huo, Y., Huang, J., Li, J., et al. (2019). Matrine improves skeletal muscle atrophy by inhibiting E3 ubiquitin ligases and activating the AKT/mTOR/FoxO3alpha signaling pathway in $\mathrm{C} 2 \mathrm{C} 12$ myotubes and mice. Oncol. Rep. 42 (2), 479-494. doi: 10.3892/or.2019.7205

Cho, Y. R., Lee, J. H., Kim, J. H., Lee, S. Y., Yoo, S., Jung, M. K., et al. (2018). Matrine suppresses KRAS-driven pancreatic cancer growth by inhibiting autophagy-mediated energy metabolism. Mol. Oncol. 12, 1203-1215. doi: 10.1002/1878-0261.12324

Cui, L., Cai, Y., Cheng, W., Liu, G., Zhao, J., Cao, H., et al. (2017). A Novel, Multi-Target Natural Drug Candidate, Matrine, Improves Cognitive Deficits in Alzheimer's Disease Transgenic Mice by Inhibiting Abeta Aggregation and Blocking the RAGE/ Abeta Axis. Mol. Neurobiol. 54, 1939-1952. doi: 10.1007/s12035-016-9783-8

Dutta, S., Mahalanobish, S., Saha, S., Ghosh, S., and Sil, P. C. (2019). Natural products: An upcoming therapeutic approach to cancer. Food Chem. Toxicol. 128, 240-255. doi: 10.1016/j.fct.2019.04.012

Fan, H., Jiang, C., Zhong, B., Sheng, J., Chen, T., Chen, Q., et al. (2018). Matrine Ameliorates Colorectal Cancer in Rats via Inhibition of HMGB1 Signaling and Downregulation of IL-6, TNF-alpha, and HMGB1. J. Immunol. Res. 2018, 5408324. doi: 10.1155/2018/5408324

Fearon, K., Strasser, F., Anker, S. D., Bosaeus, I., Bruera, E., Fainsinger, R. L., et al. (2011). Definition and classification of cancer cachexia: an international consensus. Lancet Oncol. 12, 489-495. doi: 10.1016/S1470-2045(10)70218-7

Gerber, H. P., Koehn, F. E., and Abraham, R. T. (2013). The antibody-drug conjugate: an enabling modality for natural product-based cancer therapeutics. Nat. Prod. Rep. 30, 625-639. doi: 10.1039/c3np20113a

Gu, Y. Y., Chen, M. H., May, B. H., Liao, X. Z., Liu, J. H., Tao, L. T., et al. (2018). Matrine induces apoptosis in multiple colorectal cancer cell lines in vitro and inhibits tumor growth with minimum side effects in vivo via Bcl-2 and caspase3. Phytomedicine 51, 214-225. doi: 10.1016/j.phymed.2018.10.004

Guo, Y. M., Huang, Y. X., Shen, H. H., Sang, X. X., Ma, X., Zhao, Y. L., et al. (2015). Efficacy of Compound Kushen Injection in Relieving Cancer-Related Pain: A Systematic Review and Meta-Analysis. Evid. Based. Complement Alternat. Med. 2015, 840742. doi: 10.1155/2015/840742

Guo, S., Chen, Y., Pang, C., Wang, X., Shi, S., Zhang, H., et al. (2018a). Matrine is a novel inhibitor of the TMEM16A chloride channel with antilung adenocarcinoma effects. J. Cell Physiol. 234, 8698-8708. doi: 10.1002/jcp.27529

Guo, S., Gao, C., Xiao, W., Zhang, J., Qu, Y., Li, J., et al. (2018b). Matrine Protects Cardiomyocytes From Ischemia/Reperfusion Injury by Regulating HSP70 Expression Via Activation of the JAK2/STAT3 Pathway. Shock 50, 664-670. doi: 10.1097/SHK.0000000000001108
Huang, M., and Xin, W. (2018). Matrine inhibiting pancreatic cells epithelialmesenchymal transition and invasion through ROS/NF-kappaB/MMPs pathway. Life Sci. 192, 55-61. doi: 10.1016/j.lfs.2017.11.024

Huang, W. C., Chan, C. C., Wu, S. J., Chen, L. C., Shen, J. J., Kuo, M. L., et al. (2014). Matrine attenuates allergic airway inflammation and eosinophil infiltration by suppressing eotaxin and Th2 cytokine production in asthmatic mice. J. Ethnopharmacol. 151, 470-477. doi: 10.1016/ j.jep.2013.10.065

Huang, H., T, D., Xu, G., Lai, Y., Fan, X., Chen, X., et al. (2017). Matrine suppresses invasion of castration-resistant prostate cancer cells by downregulating MMP2/9 via NF-kappaB signaling pathway. Int. J. Oncol. 50, 640-648. doi: 10.3892/ ijo.2016.3805

Huang, H., Wang, Q., T, D., Lin, C., Lai, Y., Zhu, D., et al. (2018). Matrine inhibits the progression of prostate cancer by promoting expression of GADD45B. Prostate 78, 327-335. doi: 10.1002/pros.23469

Jiang, J. H., Pi, J., Jin, H., Yang, F., and Cai, J. Y. (2018). Chinese herb medicine matrine induce apoptosis in human esophageal squamous cancer KYSE-150 cells through increasing reactive oxygen species and inhibiting mitochondrial function. Pathol. Res. Pract. 214, 691-699. doi: 10.1016/j.prp.2018.03.015

Jiang, S., Sun, J., Mohammadtursun, N., Hu, Z., Li, Q., Zhao, Z., et al. (2019). Dual role of autophagy/mitophagy in chronic obstructive pulmonary disease. Pulm. Pharmacol. Ther. 56, 116-125. doi: 10.1016/j.pupt.2019.04.002

Jin, H., Sun, Y., Wang, S., and Cheng, X. (2013). Matrine activates PTEN to induce growth inhibition and apoptosis in V600EBRAF harboring melanoma cells. Int. J. Mol. Sci. 14, 16040-16057. doi: 10.3390/ijms140816040

Kashyap, D., Tuli, H. S., Yerer, M. B., Sharma, A., Sak, K., Srivastava, S., et al. (2019). Natural product-based nanoformulations for cancer therapy: Opportunities and challenges. Semin. Cancer Biol. S1044-1579X(1019)3010330108. doi: 10.1016/j.semcancer.2019.08.014

Khan, A., Shal, B., Naveed, M., Shah, F. A., Atiq, A., Khan, N. U., et al. (2019). Matrine ameliorates anxiety and depression-like behaviour by targeting hyperammonemia-induced neuroinflammation and oxidative stress in $\mathrm{CCl} 4$ model of liver injury. Neurotoxicology 72, 38-50. doi: 10.1016/ j.neuro.2019.02.002

Kim, E. K., and Choi, E. J. (2015). Compromised MAPK signaling in human diseases: an update. Arch. Toxicol. 89, 867-882. doi: 10.1007/s00204-015-1472-2

Ko, J. H., Sethi, G., Um, J. Y., Shanmugam, M. K., Arfuso, F., Kumar, A. P., et al. (2017). The Role of Resveratrol in Cancer Therapy. Int. J. Mol. Sci. 18 (12), 2589. doi: $10.3390 / \mathrm{ijms} 18122589$

Lai, J. P., He, X. W., Jiang, Y., and Chen, F. (2003). Preparative separation and determination of matrine from the Chinese medicinal plant Sophora flavescens Ait by molecularly imprinted solid-phase extraction. Anal. Bioanal. Chem. 375, 264-269. doi: 10.1007/s00216-002-1675-2

Li, X., Zhou, R., Zheng, P., Yan, L., Wu, Y., Xiao, X., et al. (2010). Cardioprotective effect of matrine on isoproterenol-induced cardiotoxicity in rats. J. Pharm. Pharmacol. 62, 514-520. doi: 10.1211/jpp.62.04.0015

Li, Y., Zhang, J., Ma, H., Chen, X., Liu, T., Jiao, Z., et al. (2013). Protective role of autophagy in matrineinduced gastric cancer cell death. Int. J. Oncol. 42, 14171426. doi: 10.3892/ijo.2013.1817

Li, H., Xie, S., Liu, X., Wu, H., Lin, X., Gu, J., et al. (2014). Matrine alters microRNA expression profiles in SGC-7901 human gastric cancer cells. Oncol. Rep. 32, 2118-2126. doi: 10.3892/or_xxxxxxxx

Li, Y., Zhang, Z. N., Zhao, H. M., Tong, Z. C., Yang, J., Wang, H., et al. (2014). Matrine inhibits the invasive properties of human osteosarcoma cells by downregulating the ERK-NF-kappaB pathway. Anticancer Drugs 25, 10351043. doi: 10.1097/CAD.0000000000000136

Li, L., Xue, T., Xu, W., and Zhou, B. (2016). Effect of matrine combined with cisplatin on the expression of XIAP in human rhabdomyosarcoma RD cells. Oncol. Lett. 12, 3793-3798. doi: 10.3892/ol.2016.5150

Li, Q., Lai, Y., Wang, C., Xu, G., He, Z., Shang, X., et al. (2016). Matrine inhibits the proliferation, invasion and migration of castration-resistant prostate cancer cells through regulation of the NF-kappaB signaling pathway. Oncol. Rep. 35, 375-381. doi: 10.3892/or.2015.4341

Li, Y., Yao, J., Han, C., Yang, J., Chaudhry, M. T., Wang, S., et al. (2016). Quercetin, Inflammation and Immunity. Nutrients 8, 167. doi: 10.3390/nu8030167

Li, Q., Huang, H., He, Z., Sun, Y., Tang, Y., Shang, X., et al. (2018). Regulatory effects of antitumor agent matrine on FOXO and PI3K-AKT pathway in 
castration-resistant prostate cancer cells. Sci. China Life Sci. 61, 550-558. doi: $10.1007 /$ s11427-016-9050-6

Li, Y., Wang, G., Liu, J., and Ouyang, L. (2020). Quinolizidine alkaloids derivatives from Sophora alopecuroides Linn: Bioactivities, structure-activity relationships and preliminary molecular mechanisms. Eur. J. Med. Chem. 188, 111972. doi: 10.1016/j.ejmech.2019.111972

Liang, C. Z., Zhang, J. K., Shi, Z., Liu, B., Shen, C. Q., and Tao, H. M. (2012). Matrine induces caspase-dependent apoptosis in human osteosarcoma cells in vitro and in vivo through the upregulation of Bax and Fas/FasL and downregulation of Bcl-2. Cancer Chemother. Pharmacol. 69, 317-331. doi: 10.1007/s00280-011-1699-4

Liao, X. Z., Tao, L. T., Liu, J. H., Gu, Y. Y., Xie, J., Chen, Y., et al. (2017). Matrine combined with cisplatin synergistically inhibited urothelial bladder cancer cells via down-regulating VEGF/PI3K/AKT signaling pathway. Cancer Cell Int. 17, 124. doi: 10.1186/s12935-017-0495-6

Lin, Y., Lin, L., Jin, Y., Wang, D., Tan, Y., and Zheng, C. (2014). Combination of Matrine and Sorafenib Decreases the Aggressive Phenotypes of Hepatocellular Carcinoma Cells. Chemotherapy 60, 112-118. doi: 10.1159/000371736

Lin, L., Zhou, F., Shen, S., and Zhang, T. (2018). Fighting Liver Fibrosis with Naturally Occurring Antioxidants. Planta Med. 84, 1318-1333. doi: 10.1055/a0757-0008

Liu, T., Song, Y., Chen, H., Pan, S., and Sun, X. (2010). Matrine inhibits proliferation and induces apoptosis of pancreatic cancer cells in vitro and in vivo. Biol. Pharm. Bull. 33, 1740-1745. doi: 10.1248/bpb.33.1740

Liu, X. J., Cao, M. A., Li, W. H., Shen, C. S., Yan, S. Q., and Yuan, C. S. (2010). Alkaloids from Sophora flavescens Aition. Fitoterapia 81, 524-527. doi: 10.1016/j.fitote.2010.01.008

Liu, Z. W., Wang, J. K., Qiu, C., Guan, G. C., Liu, X. H., Li, S. J., et al. (2015). Matrine pretreatment improves cardiac function in rats with diabetic cardiomyopathy via suppressing ROS/TLR-4 signaling pathway. Acta Pharmacol. Sin. 36, 323-333. doi: 10.1038/aps.2014.127

Liu, H., Dong, Y., Gao, Y., Du, Z., Wang, Y., Cheng, P., et al. (2016). The Fascinating Effects of Baicalein on Cancer: A Review. Int. J. Mol. Sci. 17 (10), 1681. doi: $10.3390 /$ ijms 17101681

Liu, S. Q., Zhang, M. L., Zhang, H. J., Liu, F. Z., Chu, R. J., Zhang, G. X., et al. (2017). Matrine promotes oligodendrocyte development in CNS autoimmunity through the PI3K/AKT signaling pathway. Life Sci. 180, 3641. doi: 10.1016/j.lfs.2017.05.010

Liu, Y., Qi, Y., Bai, Z. H., Ni, C. X., Ren, Q. H., Xu, W. H., et al. (2017). A novel matrine derivate inhibits differentiated human hepatoma cells and hepatic cancer stem-like cells by suppressing PI3K/AKT signaling pathways. Acta Pharmacol. Sin. 38, 120-132. doi: 10.1038/aps.2016.104

Liu, Z., Lv, Y., Zhang, Y., Liu, F., Zhu, L., Pan, S., et al. (2017a). Matrine-Type Alkaloids Inhibit Advanced Glycation End Products Induced Reactive Oxygen Species-Mediated Apoptosis of Aortic Endothelial Cells In Vivo and In Vitro by Targeting MKK3 and p38MAPK Signaling. J. Am. Heart Assoc. 6 (12), e007441. doi: 10.1161/JAHA.117.007441

Liu, Z., Zhang, Y., Tang, Z., Xu, J., Ma, M., Pan, S., et al. (2017b). Matrine attenuates cardiac fibrosis by affecting ATF6 signaling pathway in diabetic cardiomyopathy. Eur. J. Pharmacol. 804, 21-30. doi: 10.1016/j.ejphar.2017.03.061

Liu, Z., Wang, Y., Zhu, H., Qiu, C., Guan, G., Wang, J., et al. (2018). Matrine blocks AGEs- induced HCSMCs phenotypic conversion via suppressing Dll4-Notch pathway. Eur. J. Pharmacol. 835, 126-131. doi: 10.1016/j.ejphar.2018.07.051

Liu, P., Zhu, L., Zou, G., and Ke, H. (2019). Matrine Suppresses Pancreatic Fibrosis by Regulating TGF-beta/Smad Signaling in Rats. Yonsei Med. J. 60, 79-87. doi: 10.3349/ymj.2019.60.1.79

Lu, S., Xiao, X., and Cheng, M. (2015). Matrine inhibits IL-1beta-induced expression of matrix metalloproteinases by suppressing the activation of MAPK and NF-kappaB in human chondrocytes in vitro. Int. J. Clin. Exp. Pathol. 8, 4764-4772.

Lu, Z., Xiao, Y., Liu, X., Zhang, Z., Xiao, F., and Bi, Y. (2017). Matrine reduces the proliferation of A549 cells via the p53/p21/PCNA/eIF4E signaling pathway. Mol. Med. Rep. 15, 2415-2422. doi: 10.3892/mmr.2017.6331

Ma, L., Zhu, Z., Jiang, L., Sun, X., Lu, X., Zhou, M., et al. (2015). Matrine suppresses cell growth of human chronic myeloid leukemia cells via its inhibition of the interleukin-6/Janus activated kinase/signal transducer and activator of transcription 3 signaling cohort. Leuk Lymphoma. 56, 2923-2930. doi: 10.3109/10428194.2015.1007507
Ma, Y., Zou, F., Xiong, J., Wan, W., Yin, L., Li, X., et al. (2015). Effect of Matrine on HPAC cell migration by down-regulating the expression of MT1-MMP via Wnt signaling. Cancer Cell Int. 15, 59. doi: 10.1186/s12935-015-0210-4

Ma, K., Huang, M. Y., Guo, Y. X., and Hu, G. Q. (2016). Matrine-induced autophagy counteracts cell apoptosis via the ERK signaling pathway in osteosarcoma cells. Oncol. Lett. 12, 1854-1860. doi: 10.3892/ol.2016.4848

Ma, X., Li, R. S., Wang, J., Huang, Y. Q., Li, P. Y., Wang, J., et al. (2016). The Therapeutic Efficacy and Safety of Compound Kushen Injection Combined with Transarterial Chemoembolization in Unresectable Hepatocellular Carcinoma: An Update Systematic Review and Meta-Analysis. Front. Pharmacol. 7, 70. doi: 10.3389/fphar.2016.00070

Mahzari, A., Zeng, X. Y., Zhou, X., Li, S., Xu, J., Tan, W., et al. (2018). Repurposing matrine for the treatment of hepatosteatosis and associated disorders in glucose homeostasis in mice. Acta Pharmacol. Sin. 39, 1753-1759. doi: 10.1038/s41401-018-0016-8

Massi, A., Bortolini, O., Ragno, D., Bernardi, T., Sacchetti, G., Tacchini, M., et al. (2017). Research Progress in the Modification of Quercetin Leading to Anticancer Agents. Molecules 22 (8), 1270. doi: 10.3390/molecules22081270

Mirza-Aghazadeh-Attari, M., Mohammadzadeh, A., Adib, A., Darband, S. G., Sadighparvar, S., Mihanfar, A., et al. (2019). Melatonin-mediated regulation of autophagy: Making sense of double-edged sword in cancer. J. Cell Physiol. 234, 17011-17022. doi: $10.1002 /$ jcp. 28435

Moffat, G. T., and Epstein, A. S. (2019). Pancreatic cancer-A disease in need: Optimizing and integrating supportive care. Cancer 125, 3927-3935. doi: $10.1002 /$ cncr. 32423

Newman, D. J., and Cragg, G. M. (2016). Natural Products as Sources of New Drugs from 1981 to 2014. J. Nat. Prod. 79, 629-661. doi: 10.1021/ acs.jnatprod.5b01055

Niu, H., Zhang, Y., Wu, B., Zhang, Y., Jiang, H., and He, P. (2014). Matrine induces the apoptosis of lung cancer cells through downregulation of inhibitor of apoptosis proteins and the AKT signaling pathway. Oncol. Rep. 32, 10871093. doi: $10.3892 /$ or.2014.3273

Niu, Y., Dong, Q., and Li, R. (2017). Matrine regulates Th1/Th2 cytokine responses in rheumatoid arthritis by attenuating the NF-kappaB signaling. Cell Biol. Int. 41, 611-621. doi: 10.1002/cbin.10763

Noorolyai, S., Shajari, N., Baghbani, E., Sadreddini, S., and Baradaran, B. (2019). The relation between PI3K/AKT signalling pathway and cancer. Gene 698, 120-128. doi: 10.1016/j.gene.2019.02.076

Ou, X., Chen, Y., Cheng, X., Zhang, X., and He, Q. (2014). Potentiation of resveratrol-induced apoptosis by matrine in human hepatoma HepG2 cells. Oncol. Rep. 32, 2803-2809. doi: 10.3892/or.2014.3512

Peng, X., Zhou, D., Wang, X., Hu, Z., Yan, Y., and Huang, J. (2016). Matrine Suppresses Proliferation and Invasion of SGC7901 Cells through Inactivation of PI3K/AKT/uPA Pathway. Ann. Clin. Lab. Sci. 46, 457-462.

Pires, B. R. B., Silva, R., Ferreira, G. M., and Abdelhay, E. (2018). NF-kappaB: Two Sides of the Same Coin. Genes (Basel) 9, 24. doi: 10.3390/genes9010024

Qian, L., Liu, Y., Xu, Y., Ji, W., Wu, Q., Liu, Y., et al. (2015). Matrine derivative WM130 inhibits hepatocellular carcinoma by suppressing EGFR/ERK/MMP-2 and PTEN/AKT signaling pathways. Cancer Lett. 368, 126-134. doi: 10.1016/ j.canlet.2015.07.035

Rashid, H. U., Xu, Y., Muhammad, Y., Wang, L., and Jiang, J. (2019). Research advances on anticancer activities of matrine and its derivatives: An updated overview. Eur. J. Med. Chem. 161, 205-238. doi: 10.1016/j.ejmech.2018.10.037

Rezende, P. C., Ribas, F. F., Serrano, C. V.Jr., and Hueb, W. (2019). Clinical significance of chronic myocardial ischemia in coronary artery disease patients. J. Thorac. Dis. 11, 1005-1015. doi: 10.21037/jtd.2019.02.85

Sahin, U., and Tureci, O. (2018). Personalized vaccines for cancer immunotherapy. Science 359, 1355-1360. doi: 10.1126/science.aar7112

Shao, H., Yang, B., Hu, R., and Wang, Y. (2013). Matrine effectively inhibits the proliferation of breast cancer cells through a mechanism related to the NFkappaB signaling pathway. Oncol. Lett. 6, 517-520. doi: 10.3892/ ol.2013.1399

Shao, Q., Zhao, X., and Yao, L. (2014). Matrine inhibits the growth of retinoblastoma cells (SO-Rb50) by decreasing proliferation and inducing apoptosis in a mitochondrial pathway. Mol. Biol. Rep. 41, 3475-3480. doi: 10.1007/s11033-014-3209-3

Shi, D., Zhang, J., Qiu, L., Li, J., Hu, Z., and Zhang, J. (2013). Matrine Inhibits Infiltration of the Inflammatory Grl(hi) Monocyte Subset in Injured Mouse 
Liver through Inhibition of Monocyte Chemoattractant Protein-1. Evid. Based. Complement Alternat. Med. 2013, 580673. doi: 10.1155/2013/580673

Sowndhararajan, K., Deepa, P., Kim, M., Park, S. J., and Kim, S. (2017). Baicalein as a potent neuroprotective agent: A review. BioMed. Pharmacother. 95, 10211032. doi: 10.1016/j.biopha.2017.08.135

Sugiyama, M. G., Fairn, G. D., and Antonescu, C. N. (2019). Akt-ing Up Just About Everywhere: Compartment-Specific Akt Activation and Function in Receptor Tyrosine Kinase Signaling. Front. Cell Dev. Biol. 7, 70. doi: 10.3389/ fcell.2019.00070

Sun, B., and Xu, M. (2015). Matrine inhibits the migratory and invasive properties of nasopharyngeal carcinoma cells. Mol. Med. Rep. 11, 4158-4164. doi: 10.3892/mmr.2015.3276

Sun, Y., Liu, W. Z., Liu, T., Feng, X., Yang, N., and Zhou, H. F. (2015). Signaling pathway of MAPK/ERK in cell proliferation, differentiation, migration, senescence and apoptosis. J. Recept Signal Transduct. Res. 35, 600-604. doi: 10.3109/10799893.2015.1030412

Sun, D., Wang, J., Yang, N., and Ma, H. (2016). Matrine suppresses airway inflammation by downregulating SOCS3 expression via inhibition of NFkappaB signaling in airway epithelial cells and asthmatic mice. Biochem. Biophys. Res. Commun. 477, 83-90. doi: 10.1016/j.bbrc.2016.06.024

Tan, C., Qian, X., Jia, R., Wu, M., and Liang, Z. (2013). Matrine induction of reactive oxygen species activates p38 leading to caspase-dependent cell apoptosis in nonsmall cell lung cancer cells. Oncol. Rep. 30, 2529-2535. doi: 10.3892/or.2013.2727

Tanabe, N., Kuboyama, T., and Tohda, C. (2018). Matrine Directly Activates Extracellular Heat Shock Protein 90, Resulting in Axonal Growth and Functional Recovery in Spinal Cord Injured-Mice. Front. Pharmacol. 9, 446. doi: $10.3389 /$ fphar.2018.00446

Tang, Z., Wang, Q., He, Z., Yin, L., Zhang, Y., and Wang, S. (2017). Liver, blood microdialysate and plasma pharmacokinetics of matrine following transdermal or intravenous administration. Die Pharmazie 72 (3), 167-170. doi: 10.1691/ ph.2017.6101

Tetik, V. A., Duzgun, Z., Erdem, C., Kaymaz, B. T., Eroglu, Z., and Cetintas, V. B. (2018). Matrine induced G0/G1 arrest and apoptosis in human acute T-cell lymphoblastic leukemia (T-ALL) cells. Bosn. J. Basic Med. Sci. 18 (2), 141-149. doi: 10.17305/bjbms.2017.2457

Villarino, A. V., Kanno, Y., Ferdinand, J. R., and O'shea, J. J. (2015). Mechanisms of Jak/STAT signaling in immunity and disease. J. Immunol. 194, 21-27. doi: 10.4049/jimmunol.1401867

Wang, Z., Zhang, J., Wang, Y., Xing, R., Yi, C., Zhu, H., et al. (2013). Matrine, a novel autophagy inhibitor, blocks trafficking and the proteolytic activation of lysosomal proteases. Carcinogenesis 34, 128-138. doi: 10.1093/carcin/bgs295

Wang, Q., Du, ,. H., Geng, G., Zhou, H., Xu, M., Cao, H., et al. (2014). Matrine inhibits proliferation and induces apoptosis via BID-mediated mitochondrial pathway in esophageal cancer cells. Mol. Biol. Rep. 41, 3009-3020. doi: 10.1007/ s11033-014-3160-3

Wang, H. Q., Jin, J. J., and Wang, J. (2015a). Matrine induces mitochondrial apoptosis in cisplatin-resistant non-small cell lung cancer cells via suppression of betacatenin/survivin signaling. Oncol. Rep. 33, 2561-2566. doi: 10.3892/or.2015.3844

Wang, Z., Wu, Y., Wang, Y., Jin, Y., Ma, X., Zhang, Y., et al. (2015b). Matrine inhibits the invasive properties of human glioma cells by regulating epithelialtomesenchymal transition. Mol. Med. Rep. 11, 3682-3686. doi: $10.3892 / \mathrm{mmr} .2015 .3167$

Wang, S., Lian, X., Sun, M., Luo, L., and Guo, L. (2016). Efficacy of compound Kushen injection plus radiotherapy on nonsmall-cell lungcancer: A systematic review and meta-analysis. J. Cancer Res. Ther. 12, 1298-1306. doi: 10.4103/ 0973-1482.199538

Wang, Y., Liu, Y., Jiang, J., and Cui, H. (2018a). Antitumor effects of matrine on cancer stem like cells isolated from the human liver cancer SMMC-7721 cell line. Oncol. Lett. 15, 1777-1782. doi: 10.3892/ol.2017.7531

Wang, Y., Zhang, S., Liu, J., Fang, B., Yao, J., and Cheng, B. (2018b). Matrine inhibits the invasive and migratory properties of human hepatocellular carcinoma by regulating epithelialmesenchymal transition. Mol. Med. Rep. 18, 911-919. doi: 10.3892/mmr.2018.9023

Watkins, R., Wu, L., Zhang, C., Davis, R. M., and Xu, B. (2015). Natural productbased nanomedicine: recent advances and issues. Int. J. Nanomed. 10, 60556074. doi: $10.2147 /$ ijn.s92162
Wei, R., Cao, J., and Yao, S. (2018). Matrine promotes liver cancer cell apoptosis by inhibiting mitophagy and PINK1/Parkin pathways. Cell Stress Chaperones 23, 1295-1309. doi: 10.1007/s12192-018-0937-7

Wei, Y. P., Wang, X. H., Liu, G., Zhang, J. F., Yang, Y. X., Zhang, J., et al. (2018). Matrine exerts inhibitory effects in melanoma through the regulation of miR19b-3p/PTEN. Int. J. Oncol. 53, 791-800. doi: 10.3892/ijo.2018.4414

Wu, C., Xu, Z., Gai, R., and Huang, K. (2016). Matrine ameliorates spontaneously developed colitis in interleukin-10-deficient mice. Int. Immunopharmacol. 36 , 256-262. doi: 10.1016/j.intimp.2016.04.038

Wu, J., Hu, G., Dong, Y., Ma, R., Yu, Z., Jiang, S., et al. (2017a). Matrine induces AKT/mTOR signalling inhibition-mediated autophagy and apoptosis in acute myeloid leukaemia cells. J. Cell Mol. Med. 21, 1171-1181. doi: 10.1111/ jcmm.13049

Wu, X., Zhou, J., Cai, D., and Li, M. (2017b). Matrine inhibits the metastatic properties of human cervical cancer cells via downregulating the p38 signaling pathway. Oncol. Rep. 38, 1312-1320. doi: 10.3892/or.2017.5787

Xia, N., Daiber, A., Forstermann, U., and Li, H. (2017). Antioxidant effects of resveratrol in the cardiovascular system. Int. J. Mol. Sci. 174, 1633-1646. doi: $10.1111 / \mathrm{bph} .13492$

Xiao, Y., Ma, D., Wang, H., Wu, D., Chen, Y., Ji, K., et al. (2017). Matrine Suppresses the ER-positive MCF Cells by Regulating Energy Metabolism and Endoplasmic Reticulum Stress Signaling Pathway. Phytother. Res. 31, 671-679. doi: $10.1002 /$ ptr.5785

Xiao, X., Ao, M., Xu, F., Li, X., Hu, J., Wang, Y., et al. (2018). Effect of matrine against breast cancer by downregulating the vascular endothelial growth factor via the Wnt/beta-catenin pathway. Oncol. Lett. 15, 1691-1697. doi: 10.3892/ ol.2017.7519

Xie, S. B., He, X. X., and Yao, S. K. (2015). Matrine-induced autophagy regulated by $\mathrm{p} 53$ through AMP-activated protein kinase in human hepatoma cells. Int. J. Oncol. 47, 517-526. doi: 10.3892/ijo.2015.3023

Xie, W., Lu, J., Lu, Q., Wang, X., Long, H., Huang, J., et al. (2018). Matrine inhibits the proliferation and migration of lung cancer cells through regulation of the protein kinase B/glycogen synthase kinase-3beta signaling pathways. Exp. Ther. Med. 16, 723-729. doi: 10.3892/etm.2018.6266

Xu, Y., Peng, Z., Ji, W., Li, X., Lin, X., Qian, L., et al. (2015). A Novel Matrine Derivative WM130 Inhibits Activation of Hepatic Stellate Cells and Attenuates Dimethylnitrosamine-Induced Liver Fibrosis in Rats. BioMed. Res. Int. 2015, 203978. doi: $10.1155 / 2015 / 203978$

Xu, Y., Lin, H., Zheng, W., Ye, X., Yu, L., Zhuang, J., et al. (2016). Matrine ameliorates adriamycin-induced nephropathy in rats by enhancing renal function and modulating Th17/Treg balance. Eur. J. Pharmacol. 791, 491501. doi: 10.1016/j.ejphar.2016.09.022

Xu, B., Xu, M., Tian, Y., Yu, Q., Zhao, Y., Chen, X., et al. (2017). Matrine induces RIP3-dependent necroptosis in cholangiocarcinoma cells. Cell Death Discovery 3, 16096. doi: 10.1038/cddiscovery.2016.96

Yan, P., Huang, Z., and Zhu, J. (2017). Matrine inhibits cell proliferation and induces apoptosis of human rhabdomyosarcoma cells via downregulation of the extracellular signal-regulated kinase pathway. Oncol. Lett. 14, 3148-3154. doi: 10.3892/ol.2017.6564

Yang, J., and Yao, S. (2015). JNK-Bcl-2/Bcl-xL-Bax/Bak Pathway Mediates the Crosstalk between Matrine-Induced Autophagy and Apoptosis via Interplay with Beclin 1. Int. J. Mol. Sci. 16, 25744-25758. doi: 10.3390/ijms161025744

Yang, N., Han, F., Cui, H., Huang, J., Wang, T., Zhou, Y., et al. (2015). Matrine suppresses proliferation and induces apoptosis in human cholangiocarcinoma cells through suppression of JAK2/STAT3 signaling. Pharmacol. Rep. 67, 388393. doi: $10.1016 /$ j.pharep.2014.10.016

Yang, J., He, D., Peng, Y., Zhong, H., Deng, Y., Yu, Z., et al. (2017). Matrine suppresses the migration and invasion of NSCLC cells by inhibiting PAX2induced epithelial-mesenchymal transition. Oncol. Targets Ther. 10, 52095217. doi: 10.2147/OTT.S149609

Yang, Y., Dong, Q., and Li, R. (2017). Matrine induces the apoptosis of fibroblastlike synoviocytes derived from rats with collagen-induced arthritis by suppressing the activation of the JAK/STAT signaling pathway. Int. J. Mol. Med. 39, 307-316. doi: 10.3892/ijmm.2016.2843

Yang, H., Xie, Y., Ni, J., Liu, Y., Song, R., Chen, C., et al. (2018). Association Rule Analysis for Validating Interrelationships of Combined Medication of 
Compound Kushen Injection in Treating Colon Carcinoma: A Hospital Information System-Based Real-World Study. Evid. Based. Complement Alternat. Med. 2018, 4579801. doi: 10.1155/2018/4579801

Yang, Y. (2015). Cancer immunotherapy: harnessing the immune system to battle cancer. J. Clin. Invest. 125, 3335-3337. doi: 10.1172/JCI83871

Yin, H., Que, R., Liu, C., Ji, W., Sun, B., Lin, X., et al. (2018). Survivin-targeted drug screening platform identifies a matrine derivative WM-127 as a potential therapeutics against hepatocellular carcinoma. Cancer Lett. 425, 54-64. doi: 10.1016/j.canlet.2018.03.044

Yu, J., Yang, S., Wang, X., and Gan, R. (2014). Matrine improved the function of heart failure in rats via inhibiting apoptosis and blocking beta3adrenoreceptor/ endothelial nitric oxide synthase pathway. Mol. Med. Rep. 10, 3199-3204. doi: $10.3892 / \mathrm{mmr} .2014 .2642$

Yu, L., Zhou, Y., Yang, Y., Lu, F., and Fan, Y. (2017). Efficacy and Safety of Compound Kushen Injection on Patients with Advanced Colon Cancer: A Meta-Analysis of Randomized Controlled Trials. Evid. Based. Complement Alternat. Med. 2017, 7102514. doi: 10.1155/2017/7102514

Zeng, X. Y., Wang, H., Bai, F., Zhou, X., Li, S. P., Ren, L. P., et al. (2015). Identification of matrine as a promising novel drug for hepatic steatosis and glucose intolerance with HSP72 as an upstream target. Br. J. Pharmacol. 172, 4303-4318. doi: 10.1111/bph.13209

Zhang, X. L., Xu, H. R., Chen, W. L., Chu, N. N., Li, X. N., Liu, G. Y., et al. (2009). Matrine determination and pharmacokinetics in human plasma using LC/MS/ MS. J. Chromatography B. 877, 3253-3256. doi: 10.1016/j.jchromb.2009.08.026

Zhang, J. Q., Li, Y. M., Liu, T., He, W. T., Chen, Y. T., Chen, X. H., et al. (2010). Antitumor effect of matrine in human hepatoma G2 cells by inducing apoptosis and autophagy. World J. Gastroenterol. 16, 4281-4290. doi: 10.3748/wjg.v16.i34.4281

Zhang, B., Liu, Z. Y., Li, Y. Y., Luo, Y., Liu, M. L., Dong, H. Y., et al. (2011). Antiinflammatory effects of matrine in LPS-induced acute lung injury in mice. Eur. J. Pharm. Sci. 44, 573-579. doi: 10.1016/j.ejps.2011.09.020

Zhang, Z., Wang, X., Wu, W., Wang, J., Wang, Y., Wu, X., et al. (2012). Effects of matrine on proliferation and apoptosis in gallbladder carcinoma cells (GBCSD). Phytother. Res. 26, 932-937. doi: 10.1002/ptr.3657

Zhang, J. W., Su, K., Shi, W. T., Wang, Y., Hu, P. C., Wang, Y., et al. (2013). Matrine inhibits the adhesion and migration of BCG823 gastric cancer cells by affecting the structure and function of the vasodilator-stimulated phosphoprotein (VASP). Acta Pharmacol. Sin. 34, 1084-1092. doi: 10.1038/ aps.2013.15

Zhang, S., Cheng, B., Li, H., Xu, W., Zhai, B., Pan, S., et al. (2014). Matrine inhibits proliferation and induces apoptosis of human colon cancer LoVo cells by inactivating AKT pathway. Mol. Biol. Rep. 41, 2101-2108. doi: 10.1007/s11033014-3059-z

Zhang, L., Zhang, H., Zhu, Z., Jiang, L., Lu, X., Zhou, M., et al. (2015). Matrine regulates immune functions to inhibit the proliferation of leukemic cells. Int. J. Clin. Exp. Med. 8, 5591-5600.

Zhang, Y., Liu, M., Sun, H., and Yin, K. (2015). Matrine improves cognitive impairment and modulates the balance of Th17/Treg cytokines in a rat model of Abeta1-42-induced Alzheimer's disease. Cent. Eur. J. Immunol. 40, 411-419. doi: 10.5114/ceji.2015.56961

Zhang, D., Wu, J., Liu, S., Zhang, X., and Zhang, B. (2017). Network meta-analysis of Chinese herbal injections combined with the chemotherapy for the treatment of pancreatic cancer. Med. (Baltimore) 96, e7005. doi: 10.1097/ MD.0000000000007005

Zhang, D., Ni, M., Wu, J., Liu, S., Meng, Z., Tian, J., et al. (2018a). The Optimal Chinese Herbal Injections for Use With Radiotherapy to Treat Esophageal Cancer: A Systematic Review and Bayesian Network Meta-Analysis. Front. Pharmacol. 9, 1470. doi: 10.3389/fphar.2018.01470
Zhang, D., Wu, J., Wang, K., Duan, X., Liu, S., and Zhang, B. (2018b). Which are the best Chinese herbal injections combined with XELOX regimen for gastric cancer?: A PRISMA-compliant network meta-analysis. Evid. Based. Complement Alternat. Med. 97, e0127. doi: 10.1097/MD.0000000000010127

Zhang, Y., Cui, L., Guan, G., Wang, J., Qiu, C., Yang, T., et al. (2018c). Matrine suppresses cardiac fibrosis by inhibiting the TGFbeta/Smad pathway in experimental diabetic cardiomyopathy. Mol. Med. Rep. 17, 1775-1781. doi: $10.3892 / \mathrm{mmr} .2017 .8054$

Zhang, Y., Yang, X., Qiu, C., Liu, F., Liu, P., and Liu, Z. (2018d). Matrine suppresses AGE-induced HAEC injury by inhibiting ROS-mediated NRLP3 inflammasome activation. Eur. J. Pharmacol. 822, 207-211. doi: 10.1016/ j.ejphar.2018.01.029

Zhang, S., Guo, S., Gao, X. B., Liu, A., Jiang, W., Chen, X., et al. (2019). Matrine attenuates high-fat diet-induced in vivo and ox-LDL-induced in vitro vascular injury by regulating the PKCalpha/eNOS and PI3K/AKT/eNOS pathways. J. Cell Mol. Med. 23, 2731-2743. doi: $10.1111 / \mathrm{jcmm} .14180$

Zhao, P., Zhou, R., Zhu, X. Y., Hao, Y. J., Li, N., Wang, J., et al. (2015). Matrine attenuates focal cerebral ischemic injury by improving antioxidant activity and inhibiting apoptosis in mice. Int. J. Mol. Med. 36, 633-644. doi: 10.3892/ ijmm.2015.2260

Zhao, X., Zhang, X., Lv, Y., Xu, Y., Li, M., Pan, Q., et al. (2016). Matrine downregulates IL-33/ST2 expression in the central nervous system of rats with experimental autoimmune encephalomyelitis. Immunol. Lett. 178, 97104. doi: 10.1016/j.imlet.2016.08.007

Zhao, X. B., Qin, Y., Niu, Y. L., and Yang, J. (2018). Matrine inhibits hypoxia/ reoxygenation-induced apoptosis of cardiac microvascular endothelial cells in rats via the JAK2/STAT3 signaling pathway. BioMed. Pharmacother. 106, 117124. doi: 10.1016/j.biopha.2018.06.003

Zhou, H., Xu, M., Gao, Y., Deng, Z., Cao, H., Zhang, W., et al. (2014). Matrine induces caspase-independent program cell death in hepatocellular carcinoma through bid-mediated nuclear translocation of apoptosis inducing factor. Mol. Cancer 13, 59. doi: 10.1186/1476-4598-13-59

Zhou, Y. H., Feng, J. Y., You, L. S., Meng, H. T., and Qian, W. B. (2015). Matrine and CYC116 synergistically inhibit growth and induce apoptosis in multiple myeloma cells. Chin. J. Integr. Med. 21, 635-639. doi: 10.1007/s11655-0151975-y

Zhou, B. G., Wei, C. S., Zhang, S., Zhang, Z., and Gao, H. M. (2018). Matrine reversed multidrug resistance of breast cancer MCF-7/ADR cells through PI3K/ AKT signaling pathway. J. Cell Biochem. 119, 3885-3891. doi: 10.1002/jcb.26502

Zhou, W., Wang, J., Qi, Q., Feng, Z., Huang, B., Chen, A., et al. (2018). Matrine induces senescence of human glioblastoma cells through suppression of the IGF1/PI3K/AKT/p27 signaling pathway. Cancer Med. 7, 4729-4743. doi: $10.1002 / \mathrm{cam} 4.1720$

Zhu, L., Pan, Q. X., Zhang, X. J., Xu, Y. M., Chu, Y. J., Liu, N., et al. (2016). Protective effects of matrine on experimental autoimmune encephalomyelitis via regulation of ProNGF and NGF signaling. Exp. Mol. Pathol. 100, 337-343. doi: 10.1016/j.yexmp.2015.12.006

Conflict of Interest: The authors declare that the research was conducted in the absence of any commercial or financial relationships that could be construed as a potential conflict of interest.

Copyright $\odot 2020$ Zhang, Chen, Sun, Yang, Wan and Guo. This is an open-access article distributed under the terms of the Creative Commons Attribution License (CC BY). The use, distribution or reproduction in other forums is permitted, provided the original author(s) and the copyright owner(s) are credited and that the original publication in this journal is cited, in accordance with accepted academic practice. No use, distribution or reproduction is permitted which does not comply with these terms. 